\title{
FIBRINA RICA EM PLAQUETAS NO TRATAMENTO REGENERATIVO ÓSSEO PERIODONTAL: UMA REVISÃO DE ESCOPO
}

\section{PLATELET-RICH FIBRIN IN PERIODONTAL BONE REGENERATIVE TREATMENT: A SCOPE REVIEW}

Kamily Alves de Carvalho Chiconelo Sanches ${ }^{1}$, Laryssa Macedo de Oliveira ${ }^{2}$, Magda Feres ${ }^{3}$, Juliana Ferreira ${ }^{4}$, Dimorvan Bordin ${ }^{5}$, Belén Retamal-Valdes ${ }^{6}$

Pesquisa Bibliográfica / Documental.

\author{
Submetido: 29/01/2021 \\ Aprovado: 06/02/2021
}

\section{RESUMO}

Concentrados plaquetários são compostos autógenos obtidos através da centrifugação em alta rotação do sangue venoso. Dentro dos tratamentos periodontais, eles têm sido aplicados por terem excelentes propriedades regenerativas e de neoformação óssea. Esta revisão teve por objetivo responder a seguinte pergunta foco: "Em procedimentos regenerativos ósseos periodontais, o uso da fibrina rica em plaquetas (PRF) sozinha ou combinada com biomateriais, comparada com biomateriais isoladamente, leva a alterações significativas na neoformação óssea, preenchimento de defeitos ósseos ou ganhos dimensionais? ". Uma revisão de escopo foi realizada de acordo com as normas PRISMA-ScR. As bases de dados Medline/Pubmed, Scopus e Scielo foram pesquisadas usando termos-chaves e procurando ensaios clínicos aleatorizados realizados em pacientes com diferentes tipos de defeitos ósseos periodontais, que tenham ou não recebido tratamento periodontal, onde foi aplicado em um grupo PRF isoladamente ou em associação com biomaterial, quando comparado com biomateriais isoladamente. A busca eletrônica gerou 2.497 títulos/resumos e 5 artigos foram incluídos nesta revisão. No total, 175 voluntários foram tratados. Os defeitos ósseos de duas e três paredes foram os mais comumente relatados nos estudos. O tempo de acompanhamento variou entre 6 e 12 meses. Quando o PRF foi utilizado no tratamento de defeitos periodontais houve a uma melhora mais evidente nos parâmetros clínicos, incluindo uma diminuição na profundidade do defeito e diminuição da profundidade de sondagem e ganho de inserção. Os resultados desta revisão escopo indicaram que uso de PRF sozinha ou combinada com biomateriais em procedimentos regenerativos ósseos periodontais leva a uma melhora clinicamente relevante na neoformação óssea.

PALAVRAS-CHAVES: Concentrado de plaquetas. Fibrina rica em plaquetas. Defeito periodontal. Revisão.

\footnotetext{
ABSTRACT

Platelet concentrates are autogenous compounds obtained through high-speed centrifugation of venous blood. Within periodontal treatments, have been widely applied because of their excellent regenerative and bone neoformation properties. The present review aims to answer the following

${ }^{1}$ Cirurgiã-dentista. - https://orcid.org/0000-0003-2860-7536

2 Cirurgiã-dentista, mestranda em odontologia (área de concentração em periodontia). - https://orcid.org/00000002-8683-9821

${ }^{3}$ Cirurgiã-dentista, especialista em periodontia, mestrado em periodontia, doutorado em ciências médicas e biologia oral.- https://orcid.org/0000-0002-2293-3392

4 Cirurgiã-dentista, mestranda em odontologia (área de concentração em periodontia). - https://orcid.org/00000002-7572-4842

5 Cirurgião-dentista, mestrado em Clínica Odontológica, doutorado em Clínica Odontológica. https://orcid.org/0000-0002-8466-9558

${ }^{6}$ Cirurgiã-dentista, mestrado em odontologia (área de concentração em periodontia), doutorado em odontologia (área de concentração em periodontia). - https://orcid.org/0000-0003-1444-991X
} 


\section{RECIMA21 - REVISTA CIENTÍFICA MULTIDISCIPLINAR}

FIBRINA RICA EM PLAQUETAS NO TRATAMENTO REGENERATIVO ÓSSEO PERIODONTAL: UMA REVISÃO DE ESCOPO

Kamily Alves de Carvalho Chiconelo Sanches, Laryssa Macedo de Oliveira, Magda Feres, Juliana Ferreira, Dimorvan Bordin, Belén Retamal-Valdes

focus question: "In periodontal bone regenerative procedures, does the use of platelet rich fibrin(PRF) alone or combined with biomaterials, compared with biomaterials alone, present significant changes in bone neoformation, filling defects or dimensional gains?" A scoping review was conducted following the PRISMA-ScR statement. The Medline/pubMed, Scopus and Scielo databases were searched using key terms and looking for randomized clinical trials performed on patients with different types of periodontal bone defects, whether or not they received periodontal treatment, where it was applied in a PRF group alone or in association with biomaterials, and compared with biomaterials group alone. The electronic search generated 2,497 titles/abstracts and 5 articles were included in this review. A total of 175 volunteers were treated. The most commonly reported bone defects in the studies included presented two-or three-walls. The follow-up time for the selected studies varied between 6 and 12 months. In general, when PRF was used in the treatment of periodontal defects a more evident improvement in clinical parameters was observed, including a decrease in the depth of the defect and in probing depth and attachment gain. In conclusion, the results of this scope review indicated that the use of PRF alone or combined with biomaterials in periodontal bone regenerative procedures leads to a clinically relevant improvement in bone neoformation.

KEYWORDS: Platelet concentrate. Platelet rich fibrin. Periodontal defect. Review.

\section{INTRODUÇÃO}

Os tratamentos regenerativos periodontais têm por objetivo reconstruir parcialmente ou completamente os diversos tecidos que compõe o periodonto, como o osso alveolar, ligamento periodontal e cemento. Além disso, eles auxiliam na reparação dos tecidos moles periodontais (1). Variados tipos de biomateriais têm sido utilizados nos tratamentos regenerativos, tais como: enxertos autógenos $(2,3)$, homógenos (4), e xenógenos (2). Dentro dos novos tratamentos propostos para a correção de defeitos ósseos, o uso de concentrados plaquetários tem sido amplamente aplicado por serem materiais autógenos com inúmeras propriedades indutoras de neoformação óssea e de regeneração (1).

Os concentrados plaquetários são compostos autógenos obtidos através da centrifugação em alta rotação do sangue venoso coletado do próprio paciente. Na centrifugação ocorre a separação das fases branca e vermelha do conteúdo sanguíneo, tendo como resultado um material de alta qualidade e aplicabilidade clínica (1). Grande parte dos concentrados plaquetários obtidos através deste protocolo possuem as mesmas propriedades celulares, tais como: TGF-b; IGF-1; VEGF; PDGF; FGF; EGF; PDEGF. Essas propriedades regulam e estimulam a regeneração de diversas células, especificamente aquelas associadas aos processos de fibrinogênese e angiogênese. Além disso, podem estimular a proliferação de células mesenquimais e epiteliais que potencializam outros fatores de crescimento (5).

Os concentrados plaquetários podem ser apresentados de diversas formas, tais como o PRP (plasma rico em plaquetas), PRF (fibrina rica em plaquetas), i-PRF (fibrina rica em plaquetas injetável) e L-PRF (fibrina rica em plaquetas e leucócitos). O PRP (plasma rico em plaquetas), primeiro dos concentrados descritos na literatura, se apresenta em fase líquida e conta com o 


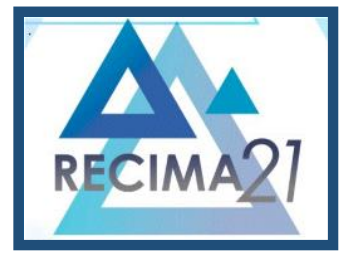

\section{RECIMA21 - REVISTA CIENTÍFICA MULTIDISCIPLINAR}

FIBRINA RICA EM PLAQUETAS NO TRATAMENTO REGENERATIVO ÓSSEO PERIODONTAL: UMA REVISÃO DE ESCOPO

Kamily Alves de Carvalho Chiconelo Sanches, Laryssa Macedo de Oliveira, Magda Feres, Juliana Ferreira, Dimorvan Bordin, Belén Retamal-Valdes

auxílio de trombina bovina em seu desenvolvimento. Neste concentrado encontramos um plasma com uma concentração de plaquetas até cinco vezes maior do que a no sangue comum (6).

No PRF temos a apresentação em forma de membrana obtida sem a necessidade da utilização de qualquer anticoagulante e onde podemos encontrar todos os componentes e fatores de crescimento anteriormente mencionados, que são extremamente favoráveis para a regeneração tecidual. Grande parte dos casos relatados na literatura mostram resultados favoráveis quanto o PRF é utilizado na correção dos defeitos ósseos periodontais (7), levantamento de seio maxilar (8) e no reparo de tecidos moles e regeneração alveolar (9). Muitos tratamentos, onde foi associado o PRF, apresentaram inclusive um aprimoramento da atividade antimicrobiana $(6,10)$. Algumas revisões avaliando a eficácia do PRF em cirurgias orais e periodontia (11), na reparação de defeitos periodontais em comparação ao debridamento com retalho aberto (9) e ainda sua atividade antimicrobiana (6) já foram publicadas. No entanto, nenhuma revisão até o momento sintetizou a informação disponível na literatura sobre estudos clínicos aleatorizados que utilizaram o PRF isoladamente ou em associação com biomateriais, comparados à utilização exclusiva de biomateriais, no tratamento de defeitos periodontais. Esses resultados podem trazer um novo olhar sobre a técnica e um importante norte para sua utilização na prática clínica odontológica. Logo, o objetivo da presente revisão foi responder a seguinte pergunta foco: "Em procedimentos regenerativos ósseos periodontais, o uso da PRF sozinha ou combinada com biomateriais, comparada com biomateriais isoladamente, leva a melhoras significativas na neoformação óssea, preenchimento de defeitos ósseos ou ganhos dimensionais? ".

\section{MÉTODOS}

Uma revisão de escopo foi realizada de acordo com as normas PRISMA-ScR (12).

\subsection{Questão PICOS}

Para realização desta revisão de escopo foi utilizada a estratégia PICOS (Population, Intervention, Comparation, Outcome e Study design):

Portanto, a pergunta foco foi:

"Em procedimentos regenerativos ósseos periodontais, o uso da PRF sozinho ou combinado com biomateriais, comparado com biomateriais isoladamente, apresenta alterações significativas na neoformação óssea, preenchimento de defeitos ou ganhos dimensionais? ".

\subsection{Critérios de elegibilidade}

ISSN: 2675-6218 - RECIMA21 - Ciências Exatas e da Terra, Sociais, da Saúde, Humanas e Engenharia/Tecnologia 


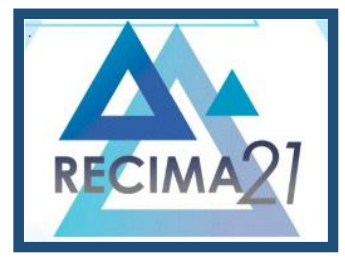

\section{RECIMA21 - REVISTA CIENTÍFICA MULTIDISCIPLINAR}

FIBRINA RICA EM PLAQUETAS NO TRATAMENTO REGENERATIVO ÓSSEO PERIODONTAL: UMA REVISÃO DE ESCOPO

Kamily Alves de Carvalho Chiconelo Sanches, Laryssa Macedo de Oliveira, Magda Feres, Juliana Ferreira, Dimorvan Bordin, Belén Retamal-Valdes

Critérios de inclusão:

Foram incluídas publicações que preenchessem os seguintes critérios:

- Ensaios clínicos aleatorizados incluindo participantes com diferentes tipos de defeitos ósseos periodontais, onde foi aplicado em um grupo (i) PRF isoladamente ou em associação com biomaterial, e no segundo grupo (ii) biomateriais isoladamente.

- Publicações em língua Inglesa.

Critérios de exclusão:

Foram excluídos artigos com as seguintes características:

- Revisões sistemáticas,

- Revisões de literatura,

- Editoriais,

- Cartas ao editor.

\subsection{Estratégia de busca}

As bases de dados eleitas para a seleção dos artigos foram: Medline (PubMed), Scopus e Scielo. A estratégia de busca utilizou como palavras-chave: "intra-bony defect" OR "intrabony defect" OR "intra-osseous defect" OR "intra-osseous defect" OR "guided bone regeneration" OR GBR OR "guided tissue regeneration" OR GTR OR "tissue engineering" OR "sinus floor elevation" OR furcation OR "intra-bony defect" OR "intrabony defect" OR "intra-osseous defect" OR "intra-osseous defect" OR "sinus floor elevation" OR furcation OR "guided bone regeneration" OR GBROR "guided tissue regeneration" OR GTR OR "tissue engineering" AND "platelet-rich fibrin" OR "platelet rich fibrin" OR "leukocyte- and platelet-rich fibrin" OR "leukocyte and platelet rich fibrin" OR "leukocyte- and platelet rich fibrin" OR "leukocyte and platelet-rich fibrin" OR PRF OR ("platelet-rich fibrin"[MeSH Terms]) OR ("platelet-rich" AND "fibrin") OR "platelet-rich fibrin" OR "I prf") OR "L PRF" AND "humans"[MeSH Terms].

\subsection{Variáveis}

As seguintes informações foram coletadas de cada estudo e registradas em formulários predefinidos: tipo de defeito ósseo, metodologia: número de pacientes, tempo de acompanhamento, características demográficas dos participantes (idade, gênero), parâmetros clínicos pré e pós intervenção (profundidade de sondagem [PS] e nível clínico de inserção [NCl]), e protocolo de tratamento.

\section{RESULTADOS}

ISSN: 2675-6218 - RECIMA21 - Ciências Exatas e da Terra, Sociais, da Saúde, Humanas e Engenharia/Tecnologia 


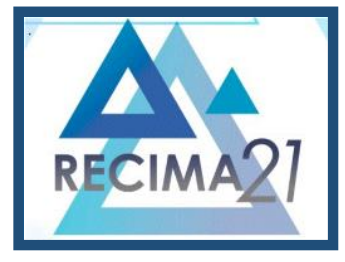

\section{RECIMA21 - REVISTA CIENTÍFICA MULTIDISCIPLINAR}

FIBRINA RICA EM PLAQUETAS NO TRATAMENTO REGENERATIVO ÓSSEO PERIODONTAL: UMA REVISÃO DE ESCOPO

Kamily Alves de Carvalho Chiconelo Sanches, Laryssa Macedo de Oliveira, Magda Feres, Juliana Ferreira, Dimorvan Bordin, Belén Retamal-Valdes

\subsection{Estudos incluídos}

A estratégia de busca gerou 2.497 títulos/resumos. Após a triagem do título e leitura do resumo, 2.463 estudos foram excluídos e 35 publicações foram avaliadas na íntegra. Destes 35 artigos, 30 foram excluídos porque não atenderam a um ou mais critérios de elegibilidade. Portanto, 5 estudos foram incluídos nesta revisão (Figura 1). A Tabela 1 apresenta os motivos de exclusão dos artigos avaliados na íntegra.

\subsection{Características metodológicas dos estudos incluídos e características demográficas da população avaliada.}

Os estudos selecionados nesta revisão foram publicados entre os anos de 2012 e 2017 na Índia, Turquia, Estados Unidos e Sérvia. Os tipos de ensaios clínicos randomizados foram desenho paralelo e boca dividida. Todos apresentaram como objetivo a avaliação da regeneração óssea periodontal utilizando PRF e biomaterial de comparação (Tabela 2).

\subsection{Dados clínicos}

No total, 175 voluntários foram tratados nos artigos incluídos. Os defeitos ósseos de duas e três paredes foram os mais comumente relatados nos estudos. Os critérios de inclusão variaram entre evidências radiográficas da presença de defeitos intraósseos, intervalo de idade dos pacientes, ausência de comprometimento sistêmico, boa higiene oral e parâmetros clínicos, como PS e NCI. Os pacientes foram divididos em dois grupos, teste e controle, com uma variação de participantes entre 15 e 21 pacientes em cada grupo. O grupo teste normalmente foi tratado por meio da PRF e o grupo controle com biomaterial isoladamente. Todos os estudos apresentaram variáveis primárias e secundárias com exceção do trabalho de Lekovic et al (13). O tempo de follow-up dos trabalhos selecionados variou entre 6 e 12 meses (Tabela 3).

A Tabela 4 apresenta os principais resultados clínicos dos estudos incluídos nesta revisão. Os diferentes estudos usaram variáveis primárias de resultado diversas para tentar avaliar a eficácia dos tratamentos. De forma geral, o uso de PRF no tratamento de defeitos periodontais levou a uma melhora mais evidente nos parâmetros clínicos, incluindo uma diminuição na profundidade do defeito, acompanhado em um ganho de inserção e diminuição da profundidade de sondagem. Características inflamatórias dos tecidos periodontais moles também foram registradas nos estudos.

\section{DISCUSSÃO}

Esta é a primeira revisão de escopo a avaliar o peso atual da evidência do uso da PRF sozinha ou combinada com biomateriais em procedimentos regenerativos ósseos periodontais. Os resultados 


\section{RECIMA21 - REVISTA CIENTÍFICA MULTIDISCIPLINAR}

FIBRINA RICA EM PLAQUETAS NO TRATAMENTO REGENERATIVO ÓSSEO PERIODONTAL: UMA REVISÃO DE ESCOPO Kamily Alves de Carvalho Chiconelo Sanches, Laryssa Macedo de Oliveira, Magda Feres, Juliana Ferreira, Dimorvan Bordin, Belén Retamal-Valdes

indicaram que o uso de PRF leva a uma melhora significativa em vários parâmetros, em comparação aos procedimentos regenerativos que não incluíram o uso da PRF. Os principais benefícios foram observados na neoformação óssea e preenchimento de defeitos ou ganhos dimensionais; incluindo diminuição na profundidade do defeito acompanhado de um ganho de inserção clínica e diminuição da profundidade de sondagem.

Algumas revisões anteriores já foram publicadas sobre esse tema, porém, esses estudos não acessaram diretamente a regeneração óssea. Foram analisadas, por exemplo, a eficácia da PRF em cirurgias orais e em periodontia (11), a eficácia em reparação de defeitos periodontais em comparação ao debridamento com retalho aberto (9) e ainda, a sua atividade antimicrobiana (6). De forma geral, esses estudos mostraram resultados promissores para a PRF também para o tratamento dessas condições clínicas. A eficácia desse tratamento na reparação de defeitos periodontais corrobora de certa maneira com os dados da presente revisão. Nossos dados mostraram por meio de uma avaliação minuciosa de todos os estudos clínicos aleatorizados sobre o tema que o uso da PRF melhora os resultados clínicos dos procedimentos ósseo regenerativos. Esses dados reforçam o potencial angiogênico e promotor do desenvolvimento celular fornecido por fatores de crescimento e citocinas liberadas de forma sustentada com o uso de PRF. Em comparação com outros biomateriais, o PRF destaca-se pela sua origem autóloga e a ausência de efeitos adversos conhecidos (1). Essas características foram claramente observadas nos ensaios clínicos incluídos nesta revisão, que em geral mostraram resultados clínicos favoráveis. Agarwal et al (14), publicaram o estudo clínico com o maior tempo de acompanhamento. Esses autores mostraram que defeitos ósseos periodontais tratados com DFDBA + PRF podem ter em média um ganho de inserção clínico e uma diminuição associada na profundidade de sondagem maior que 3 $\mathrm{mm}$ aos 12 meses de acompanhamento. Esses valores são superiores aos encontrados em defeitos ósseos tratados apenas com DFDBA + solução salina (14).

O presente trabalho apresenta vários pontos fortes: representa um dos desenhos de estudo com maior peso da evidência, pois envolveu uma busca sistemática da literatura e incluiu apenas estudos clínicos aleatorizados. A principal limitação desta revisão de escopo foi a falta de estandardização na seleção de uma variável primária de resposta. Ainda quando foi selecionado a "Neoformação óssea, preenchimento de defeitos ou ganhos dimensionais" como desfecho da revisão, na prática clínica ainda não está estandardizado a variável apropriada para medição desses ganhos ósseos. Atualmente, muitas variáveis usadas na clínica podem representar esse conceito. Esse é um dos grandes desafios da periodontia: selecionar variáveis que consigam representar um real sucesso após a terapia de diferentes condições ou doenças.

As revisões sistemáticas em saúde buscam por melhores evidências sobre uma intervenção, programa ou política de saúde. Sendo assim, seus resultados são considerados como instrumentos de confiabilidade (15). Nesse sentido, as revisões de escopo devem ser estimuladas para que 


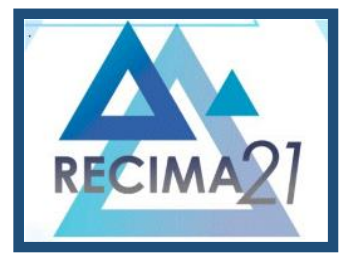

\section{RECIMA21 - REVISTA CIENTÍFICA MULTIDISCIPLINAR}

FIBRINA RICA EM PLAQUETAS NO TRATAMENTO REGENERATIVO ÓSSEO PERIODONTAL: UMA REVISÃO DE ESCOPO
Kamily Alves de Carvalho Chiconelo Sanches, Laryssa Macedo de Oliveira, Magda Feres,
Juliana Ferreira, Dimorvan Bordin, Belén Retamal-Valdes

possamos mapear evidências, possibilitando avaliações qualitativas, sistemáticas e objetivas da literatura já disponível sobre os mais diversos temas. Isto permite gerar evidência confiável para as decisões na prática clínica.

\section{CONCLUSÃO}

Os resultados desta revisão escopo indicaram que uso de PRF sozinha ou combinada com biomateriais em procedimentos regenerativos ósseos periodontais leva a uma melhora clinicamente relevante na neoformação óssea.

\section{REFERÊNCIAS}

1. Mayol M, Andrade E, Retamal-Valdes B, Bueno L, lurovschi R. Fibrina Rica en Plaquetas y Leucocitos en el tratamiento de defectos intra-óseos: Revisión Narrativa. Revista Clínica PIRO. 2018;11(1):54-57.

2. Fardin AC, Jardim ECG, Pereira FC, Guskuma MH, Aranega AM, Garcia Junior IR. Enxerto ósseo em odontologia: revisão de literatura. Innov Implant J, Biomater Esthet. 2010;5(3):48-52.

3. Martin V, Bettencourt A. Bone regeneration: Biomaterials as local delivery systems with improved osteoinductive properties. Material, Science and Engineering. 2018;82(1):363-371.

4. Kothiwale S, Bhimani R, Kaderi M, Ajbani J. Comparative study of DFDBA and FDBA block grafts in combination with chorion membrane for the treatment of periodontal intra-bony defects at 12 months post-surgery. Cell Tissue Bank. 2019;21(1).

5. Kang, YH, Park YJ, Coung YH, Kim ES, Jeon SM, Chung JH, Choung HW, Choung PH. Platelet-rich Firbrin is a Biscaffold and Reservoir of Growth Factors for Tissue Regeneration. Tissue Engineering Part A. 2011;17(3-4):349-359.

6. D'asta F, Halstead F, Harrison P, Orlandini SZ, Moiemen N, Lord J. The contribution of leucocytes to the antimicrobial activity of platelet-rich plasma preparations: A systematic review. Platelets Journal. 2016;29(1):9-20.

7. Pradeep AR, Bajaj P, Rao NS, Agarwal E, Naik SB. Platelet-Rich Fibrin Combined With a Porous Hydroxyapatite Graft for the Treatment of 3 -Wall Intrabony Defects in Chronic Periodontitis: A Randomized Controlled Clinical Trial. J Periodontol. 2017;88(12):1288-1296.

8. Olgun E, Ozkan SY, Atmaca HT, Yalim M, Hendek MK. Comparison of the clinical, radiographic, and histological effects of titanium-prepared platelet rich fibrin to allograft materials in sinus-lifting procedures. J Investig Clin Dent. 2018;9(4):e12347.

9. Shah M, Deshpande N, Bharwani A, Nadig P, Doshi V, Dave D. Effectiveness of autologous platelet-rich fibrin in the treatment of intra-bony defects: A systematic review and meta-analysis. J Indian Soci Periodontol. 2014;18(6)698-704.

10. Bielecki TM, Gazdzik TS, Arendt J, Szczepanski J, Kròl W, Wielkoszynski T. Antibacterial effect of autologous platelet gel enriched with growth factors and other active substances. J Bone Joint Surg Br. 2007;89B(3):417-420. 


\section{RECIMA21 - REVISTA CIENTÍFICA MULTIDISCIPLINAR}

FIBRINA RICA EM PLAQUETAS NO TRATAMENTO REGENERATIVO ÓSSEO PERIODONTAL: UMA REVISÃO DE ESCOPO

Kamily Alves de Carvalho Chiconelo Sanches, Laryssa Macedo de Oliveira, Magda Feres, Juliana Ferreira, Dimorvan Bordin, Belén Retamal-Valdes

11. Orozco AV, Gómez CA, Ninin LJ, Celis M. Efectividad de los concentrados plaquetarios (PRP, PRF y PRFC) para la regeneración ósea en cirugía bucal y periodontal. Una revisión sistemática. Revency. 2016:253-252.

12. Tricco AC, Lillie E, Zarin W, O'Brien KK, Colquhoun H, Levac D, Moher D, Peters MDJ, Horsley T, Weeks L, Hempel S, Akl EA, Chang C, McGowan J, Stewart L, Hartling L, Aldcroft A, Wilson MG, Garritty C, Lewin S, Godfrey CM, Macdonald MT, Langlois EV, Soares-Weiser K, Moriarty J, Clifford T, Tunçalp Ö, Straus SE. PRISMA Extension for Scoping Reviews (PRISMA-ScR): Checklist and Explanation. Ann Intern Med. 2018.

13. Lekovic V, Milinkovic I, Aleksic Z, Jankovic S, Stankovic P, Kenney EB, Camargo PM. Plateletrich fibrin and bovine porous bone mineral vs. platelet- rich fibrin in the treatment of intrabony periodontal defects. J Periodontal Res. 2012 Aug;47(4):409-17.

14. Agarwal A, Gupta ND, Jain A. Platelet rich fibrin combined with decalcified freeze-dried bone allograft for the treatment of human intrabony periodontal defects: a randomized split mouth clinical trail. Acta Odontol Scand. 2016;74(1):36-43.

15. Cordeiro L, Soares CB. Revisão de escopo: potencialidades para a síntese de metodologias utilizadas em pesquisa primária qualitativa / Scoping review: potentialities for a synthesis of methodologies used in qualitative primary research. BIS, Bol. Inst. Saúde. 2019;20(2):37-43.

16. Sezgin Y, Uraz A, Taner IL, Çulhaoğlu R. Effects of platelet-rich fibrin on healing of intra-bony defects treated with anorganic bovine bone mineral. Braz Oral Res. 2017;31(15):1807-3107.

17. Chadwick JK, Mills MP, Mealey BL. Clinical and Radiographic Evaluation of Demineralized Freeze-Dried Bone Allograft Versus Platelet-Rich Fibrin for the Treatment of Periodontal Intrabony Defects in Humans. J Periodontol. 2016;87(11):1253-1260. 


\section{RECIMA21 - REVISTA CIENTÍFICA MULTIDISCIPLINAR}

FIBRINA RICA EM PLAQUETAS NO TRATAMENTO REGENERATIVO ÓSSEO PERIODONTAL: UMA REVISÃO DE ESCOPO

Kamily Alves de Carvalho Chiconelo Sanches, Laryssa Macedo de Oliveira, Magda Feres, Juliana Ferreira, Dimorvan Bordin, Belén Retamal-Valdes

\section{FIGURAS}
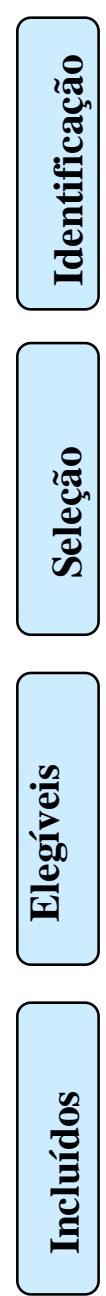

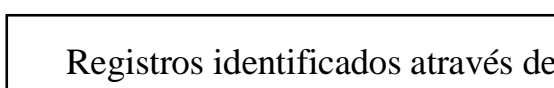
busca em bases de dados MEDLINE/SCOPUS/SCIELO $(\mathrm{n}=2.497)$
Registros adicionais identificados através de outras fontes (referências bibliográficas) $(n=3)$

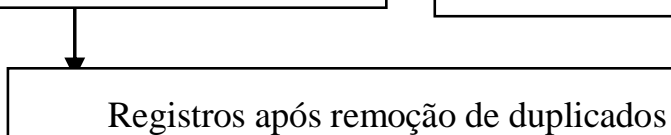

$$
(\mathrm{n}=2.498)
$$

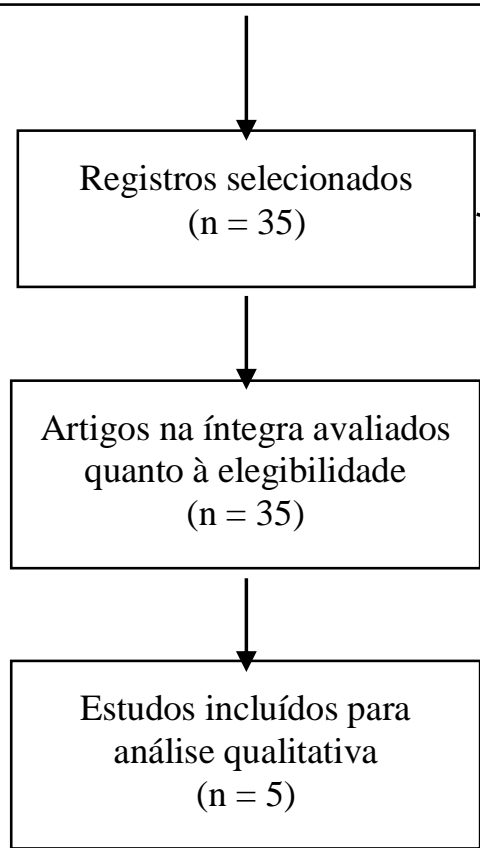

Figura 1. Diagrama de fluxo PRISMA 2009.

\section{TABELAS}

Tabela 1. Motivo de exclusão dos artigos na fase full-text.

\begin{tabular}{c|l}
\hline \multicolumn{1}{c|}{ Motivo } & \multicolumn{1}{c}{ Referências } \\
\hline Texto completo indisponível & $\begin{array}{l}\text { Galav S. et al, 2016; Wanikar I. et al, 2018; Attar BM. et al, } \\
\text { 2016; Park JH. et al, 2016. }\end{array}$ \\
\hline
\end{tabular}




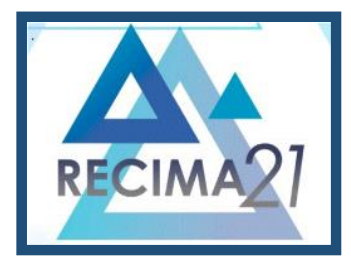

\section{RECIMA21 - REVISTA CIENTÍFICA MULTIDISCIPLINAR}

FIBRINA RICA EM PLAQUETAS NO TRATAMENTO REGENERATIVO ÓSSEO PERIODONTAL: UMA REVISÃO DE ESCOPO

Kamily Alves de Carvalho Chiconelo Sanches, Laryssa Macedo de Oliveira, Magda Feres, Juliana Ferreira, Dimorvan Bordin, Belén Retamal-Valdes

Sem grupo com biomaterial de comparação

Asimuddin S. et al, 2017; Patel GK. et al, 2017; Kanoriya D.

et al, 2016; Kanoriya D. et al, 2016; Chatterjee A. et al, 2017;

Pradeep AR. et al, 2016; Turkal HÁ et al, 2016; Martande SS.

et al, 2016; Pradeep AR. et al, 2015; Gupta S. et al, 2014.

Defeito alveolar

Hartlev J. et al, 2019; Kumar NG. et al, 2018; Saruhan N. et

al, 2017; Shawky A. \& Seifeldin SA., 2015.

Pichotano EC. et al, 2018; Olgun E. et al, 2018; Nizam N. et

Defeito em seio maxilar

al, 2017; Bolukbasi N. et al, 2015; Zhang Y. et al, 2012.

\begin{tabular}{l|l}
\hline Reparação de palato após remoção de EGL & Bahammam MA, 2017; Femminella B. et al, 2016. \\
\hline Aumento anterior de maxila & Moussa M. et al, 2016. \\
\hline Implante & Öncü E. \& Alaaddinoğlu E., 2015; Angelo T. et al, 2015. \\
\hline Recessão gengival & Jankovic S. et al, 2010; Culhaoglu R. et al, 2018. \\
\hline Duplicado & Sezgin Y. et al, 2017. \\
\hline Reconstrução de maxila & Tatullo M. et al, 2012. \\
\hline
\end{tabular}

EGL: Enxerto gengival livre

Tabela 2. Características gerais dos artigos incluídos.

\begin{tabular}{|c|c|c|c|c|c|}
\hline Referência & Ano & Pais & Local & $\begin{array}{l}\text { Desenho do } \\
\text { estudo }\end{array}$ & Objetivo \\
\hline Pradeep et al (7) & 2017 & Índia & $\begin{array}{l}\text { Departamento de } \\
\text { periodontia da } \\
\text { Government Dental } \\
\text { College and } \\
\text { Research Institute }\end{array}$ & ECR & $\begin{array}{l}\text { O presente estudo tem por } \\
\text { objetivo explorar a } \\
\text { efetividade clínica e } \\
\text { radiográfica do PRF autólogo } \\
\text { versus PRF+HA no } \\
\text { tratamento de DIOs em } \\
\text { pacientes com periodontite } \\
\text { crônica. }\end{array}$ \\
\hline Sezgin et al (16) & 2017 & Turquia & $\begin{array}{l}\text { Departamento de } \\
\text { periodontia Gazi } \\
\text { University }\end{array}$ & $\begin{array}{c}\text { ECR } \\
\text { boca dividida }\end{array}$ & $\begin{array}{l}\text { Comparar a cura de defeitos } \\
\text { ósseos periodontais tratados } \\
\text { com ABBM-PRF combinados } \\
\text { ou com ABBM isoladamente. }\end{array}$ \\
\hline Chadwick et al (17) & 2016 & EUA & $\begin{array}{c}\text { Clínica de graduação } \\
\text { da universidade } \\
\text { UTHSCSA }\end{array}$ & $\begin{array}{c}\text { ECR } \\
\text { paralelo }\end{array}$ & $\begin{array}{l}\text { O objetivo deste estudo é } \\
\text { reportar mudanças no NCl e } \\
\text { ganho ósseo em DIOs } \\
\text { tratados com DFDBA } \\
\text { comparados com PRF em } \\
\text { humanos. }\end{array}$ \\
\hline
\end{tabular}




\section{RECIMA21 - REVISTA CIENTÍFICA MULTIDISCIPLINAR}

FIBRINA RICA EM PLAQUETAS NO TRATAMENTO REGENERATIVO ÓSSEO PERIODONTAL: UMA REVISÃO DE ESCOPO

Kamily Alves de Carvalho Chiconelo Sanches, Laryssa Macedo de Oliveira, Magda Feres, Juliana Ferreira, Dimorvan Bordin, Belén Retamal-Valdes

\begin{tabular}{|c|c|c|c|c|c|}
\hline Agarwal et al (14) & 2016 & Índia & $\begin{array}{l}\text { Departamento de } \\
\text { periodontia da Dr Z. } \\
\text { A. Dental } \\
\text { College }\end{array}$ & $\begin{array}{c}\text { ECR } \\
\text { boca dividida }\end{array}$ & $\begin{array}{l}\text { O objetivo do presente } \\
\text { estudo é avaliar a efetividade } \\
\text { do DFDBA adjunto com o } \\
\text { PRF no tratamento de } \\
\text { defeitos intraósseos } \\
\text { periodontais em humanos. }\end{array}$ \\
\hline Lekovic et al (13) & 2012 & Sérvia & $\begin{array}{l}\text { Departamento de } \\
\text { periodontia da escola } \\
\text { de odontologia da } \\
\text { University of } \\
\text { Belgrade }\end{array}$ & $\begin{array}{c}\text { ECR } \\
\text { boca dividida }\end{array}$ & $\begin{array}{l}\text { O objetivo deste estudo é } \\
\text { avaliar a aplicabilidade do } \\
\text { PRF autólogo como } \\
\text { tratamento para defeitos } \\
\text { ósseos periodontais em } \\
\text { humanos e avaliar a } \\
\text { efetividade do BPBM para } \\
\text { aumentar os efeitos } \\
\text { regenerativos do PRF } \\
\text { enxertado. }\end{array}$ \\
\hline
\end{tabular}

DIO: Defeitos intraósseos; AH: Ácido hialurônico; ECR: Estudo clínico randomizado; PRF: Fibrina rica em plaquetas; NCl: Nível clínico de inserção; DFDBA: Demineralized freeze-dried bone allograft; BPBM: Bovine porus bone mineral; ABBM: Anorganic bovine bone mineral 


\section{RECIMA21 - REVISTA CIENTÍFICA MULTIDISCIPLINAR}

FIBRINA RICA EM PLAQUETAS NO TRATAMENTO REGENERATIVO ÓSSEO PERIODONTAL: UMA REVISÃO DE ESCOPO Kamily Alves de Carvalho Chiconelo Sanches, Laryssa Macedo de Oliveira, Magda Feres, uliana Ferreira, Dimorvan Bordin, Belén Retamal-Valdes

Tabela 3. Características metodológicas dos artigos selecionados

\begin{tabular}{|c|c|c|c|c|c|c|c|c|}
\hline Referência & Tipo de defeito & Critérios de inclusão & $\begin{array}{c}\text { Grupos } \\
\text { de } \\
\text { estudos }\end{array}$ & Protocolos de tratamento & $\begin{array}{c}\mathrm{N}^{\circ} \text { de } \\
\text { pacientes }\end{array}$ & $\begin{array}{l}\text { Variável } \\
\text { primaria }\end{array}$ & $\begin{array}{c}\text { Variáveis } \\
\text { secundarias }\end{array}$ & $\begin{array}{c}\text { Tempo de } \\
\text { acompanha } \\
\text { mento }\end{array}$ \\
\hline
\end{tabular}




\section{RECIMA21 - REVISTA CIENTÍFICA MULTIDISCIPLINAR}

FIBRINA RICA EM PLAQUETAS NO TRATAMENTO REGENERATIVO ÓSSEO PERIODONTAL: UMA REVISÃO DE ESCOPO Kamily Alves de Carvalho Chiconelo Sanches, Laryssa Macedo de Oliveira, Magda Feres, uliana Ferreira, Dimorvan Bordin, Belén Retamal-Valdes

\begin{tabular}{|c|c|c|c|c|c|c|c|c|}
\hline $\begin{array}{l}\text { Pradeep et } \\
\text { al (7) }\end{array}$ & $\begin{array}{l}\text { Defeitos } \\
\text { interproximais } \\
\text { com } 3 \text { paredes } \geq \\
3 \mathrm{~mm} \text { de } \\
\text { profundidade com } \\
\text { PS interproximal } \geq \\
5 \mathrm{~mm}\end{array}$ & $\begin{array}{l}\text { Os critérios de } \\
\text { inclusão foram } \\
\text { presença de defeitos } \\
\text { ósseos de três } \\
\text { paredes com } \\
\text { profundidade } \geq 3 \\
\text { mm (distância entre } \\
\text { a crista alveolar e a } \\
\text { base do defeito na } \\
\text { radiografia } \\
\text { periapical) com PS } \\
\text { interproximal } \geq 5 \mathrm{~mm} \\
\text { após a terapia da } \\
\text { fase } 1 \text { (RAR). }\end{array}$ & $\begin{array}{l}\text { Teste: } \\
\text { [PRF] } \\
\text { [PRF+HA } \\
] \\
\text { Controle: } \\
\text { [RAR] }\end{array}$ & $\begin{array}{l}\text { [PRF] No grupo PRF, uma membrana de } \\
\text { tamanho adequado foi colocada no defeito } \\
\text { intraósseo e o outra foi usada para preparar a } \\
\text { membrana que cobriu o defeito. Os retalhos } \\
\text { mucoperiosteais foram reposicionados e } \\
\text { fixados no lugar usando fios de seda não } \\
\text { absorvíveis 3-0. Suturas interrompidas ou tipo } \\
\text { sling foram colocadas e a área cirúrgica foi } \\
\text { protegida e coberta com curativo periodontal. } \\
\text { [PRF+HA] No grupo PRF+HA, grânulos de HA } \\
\text { com tamanhos de partícula de } 600-700 \text { mícrons } \\
\text { foram misturados com PRF na proporção de } 1 \text { : } \\
1 \text { (v/v). A mistura PRF-HA foi colocada no } \\
\text { defeito. Foi tomado cuidado para não colocar } \\
\text { material além do necessário nos defeitos. Uma } \\
\text { membrana de PRF comprimida foi aparada e } \\
\text { adaptada sobre o defeito enxertado. } \\
\text { [RAR] A antissepsia intraoral foi realizada com } \\
\text { enxágue de digluconato de clorexidina } 0,12 \% \text { e } \\
\text { utilizou-se solução de iodo para realização da } \\
\text { antissepsia extraoral. Após a administração de }\end{array}$ & $\begin{array}{l}\text { Teste: } \\
\text { [PRF] } 21 \\
{[\mathrm{PRF}+\mathrm{HA}]} \\
21 \\
\text { Controle: } \\
\text { [RAR] } 20\end{array}$ & $\begin{array}{l}\text { NMG }(\mathrm{mm}) \\
\text { Profundidad } \\
\text { e DIO (mm) }\end{array}$ & $\begin{array}{l}\mathrm{PS}(\mathrm{mm}) \\
\mathrm{NCl}(\mathrm{mm}) \\
\text { ISSm } \\
\text { (score) } \\
\text { Índice de } \\
\text { placa } \\
\text { (score) }\end{array}$ & 9 meses \\
\hline
\end{tabular}




\section{RECIMA21 - REVISTA CIENTÍFICA MULTIDISCIPLINAR}

FIBRINA RICA EM PLAQUETAS NO TRATAMENTO REGENERATIVO ÓSSEO PERIODONTAL: UMA REVISÃO DE ESCOPO Kamily Alves de Carvalho Chiconelo Sanches, Laryssa Macedo de Oliveira, Magda Feres, Juliana Ferreira, Dimorvan Bordin, Belén Retamal-Valdes

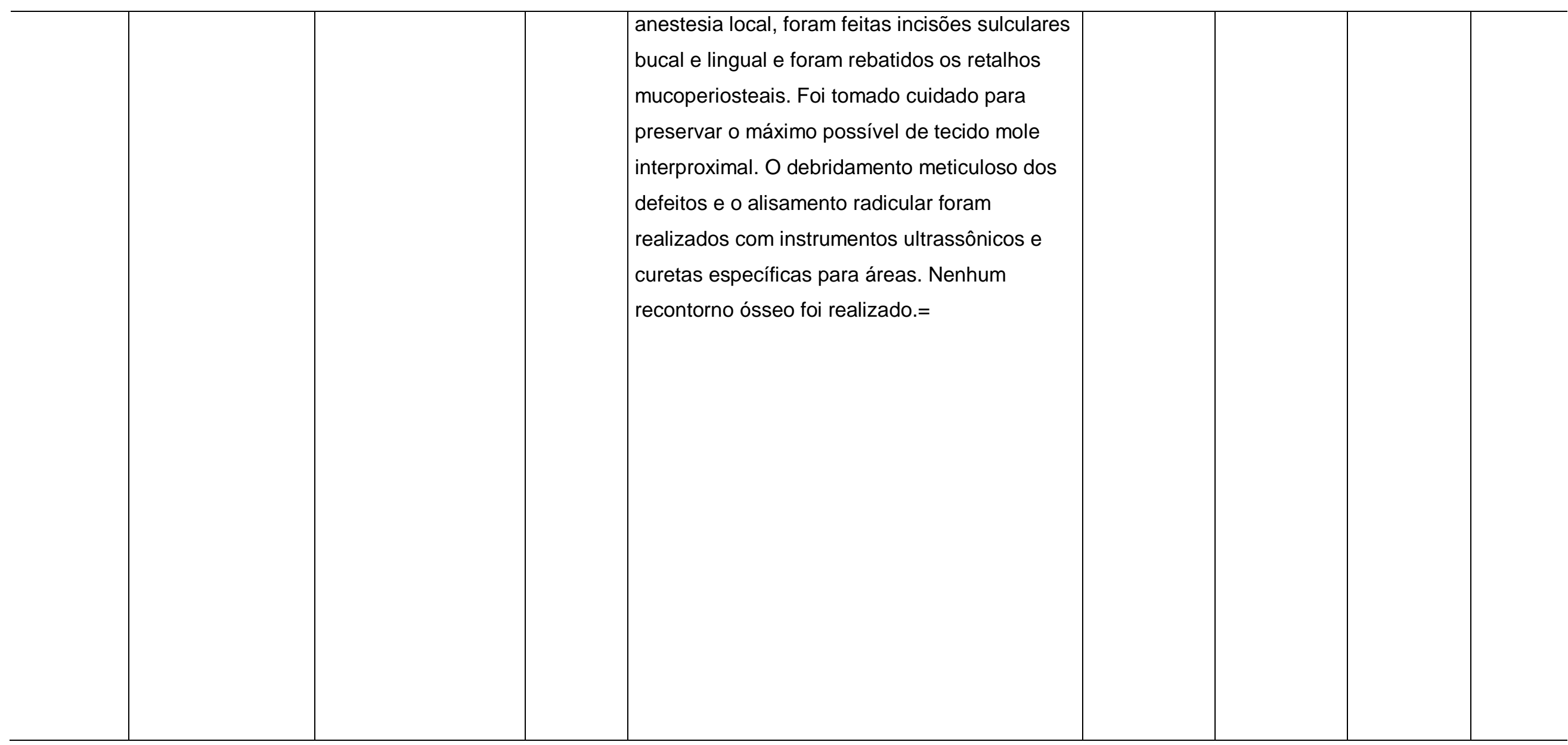




\section{RECIMA21 - REVISTA CIENTÍFICA MULTIDISCIPLINAR}

FIBRINA RICA EM PLAQUETAS NO TRATAMENTO REGENERATIVO ÓSSEO PERIODONTAL: UMA REVISÃO DE ESCOPO Kamily Alves de Carvalho Chiconelo Sanches, Laryssa Macedo de Oliveira, Magda Feres,
Juliana Ferreira, Dimorvan Bordin, Belén Retamal-Valdes

\begin{tabular}{|c|c|c|c|c|c|c|c|c|}
\hline $\begin{array}{l}\text { Sezgin et } \\
\text { al (16) }\end{array}$ & $\begin{array}{l}\text { Periodontite } \\
\text { crônica e severa } \\
\text { classificadas } \\
\text { como } \\
\text { generalizadas } \\
\text { com > 30\% dos } \\
\text { sítios afetados } \\
\text { com perda de } \mathrm{NCl} \\
\geq 5 \mathrm{~mm}\end{array}$ & $\begin{array}{l}\text { Os critérios de } \\
\text { inclusão foram: sem } \\
\text { doenças sistêmicas; } \\
\text { bom nível de higiene } \\
\text { oral (índice de placa } \\
<0.15) \text {; presença de } \\
\text { dois defeitos } \\
\text { intraósseos } \\
\text { emparelhados com } \\
\text { duas ou três paredes } \\
\text { com PS } \geq 6 m m \text { e } \\
\text { defeito intraósseo } \geq 3 \\
\text { mm, conforme } \\
\text { detectado nas } \\
\text { radiografias; sem } \\
\text { defeitos intraósseos } \\
\text { com extensão até a } \\
\text { área de furca; } \\
\text { mobilidade dental } \\
\leq 1 \text {; dente principal e } \\
\text { adjacentes com }\end{array}$ & $\begin{array}{l}\text { Teste: } \\
\text { [PRF+AB } \\
\text { BM] } \\
\text { Controle: } \\
\text { [ABBM] }\end{array}$ & $\begin{array}{l}\text { [PRF+ABBM] Após anestesia local, incisões } \\
\text { sulculares bucais e linguais foram feitas e os } \\
\text { retalhos mucoperiosteais foram elevados. O } \\
\text { retalho foi estendido um ou dois dentes } \\
\text { mesialmente ou distalmente para obter melhor } \\
\text { acesso ao local da cirurgia. O tecido de } \\
\text { granulação foi removido dos defeitos, e as } \\
\text { raízes foram dimensionadas e aplainadas } \\
\text { usando instrumentos manuais; no entanto, as } \\
\text { superfícies das raízes não foram } \\
\text { condicionadas. Uma membrana de PRF foi } \\
\text { cortada por tesouras para produzir pequenos } \\
\text { pedaços e depois misturar com ABBM de } \\
\text { grânulos com tamanho de partícula de } 0,25-1 \\
\text { mm (Bio-Oss, Gesitlich, Suíça) em um pote } \\
\text { dappen estéril; esta mistura foi adicionada ao } \\
\text { defeito com o uso de uma cureta estéril. O } \\
\text { defeito foi preenchido até a crista alveolar. A } \\
\text { outra membrana de PRF foi usada para cobrir o } \\
\text { defeito como barreira. } \\
\text { [ABBM] O ABBM foi preparado despejando as }\end{array}$ & $\begin{array}{l}\text { Teste: } \\
\text { [PRF+ABB } \\
\text { M] } 15 \\
\text { Controle: } \\
\text { [ABBM] } 15\end{array}$ & $\begin{array}{l}\text { PS (mm) } \\
\text { RG (mm) } \\
\mathrm{NCl}(\mathrm{mm}) \\
\text { Perda óssea } \\
\text { vertical } \\
\text { (mm) } \\
\text { Profundidad } \\
\text { e do defeito } \\
\text { (mm) } \\
\text { Angulação } \\
\text { do defeito } \\
\left(^{\circ}\right)\end{array}$ & $\begin{array}{l}\text { Índice de } \\
\text { placa } \\
\text { (score) } \\
\text { Índice } \\
\text { gengival } \\
\text { (score) }\end{array}$ & 6 meses \\
\hline
\end{tabular}




\section{RECIMA21 - REVISTA CIENTÍFICA MULTIDISCIPLINAR}

FIBRINA RICA EM PLAQUETAS NO TRATAMENTO REGENERATIVO ÓSSEO PERIODONTAL: UMA REVISÃo DE ESCOPO Kamily Alves de Carvalho Chiconelo Sanches, Laryssa Macedo de Oliveira, Magda Feres, Juliana Ferreira, Dimorvan Bordin, Belén Retamal-Valdes

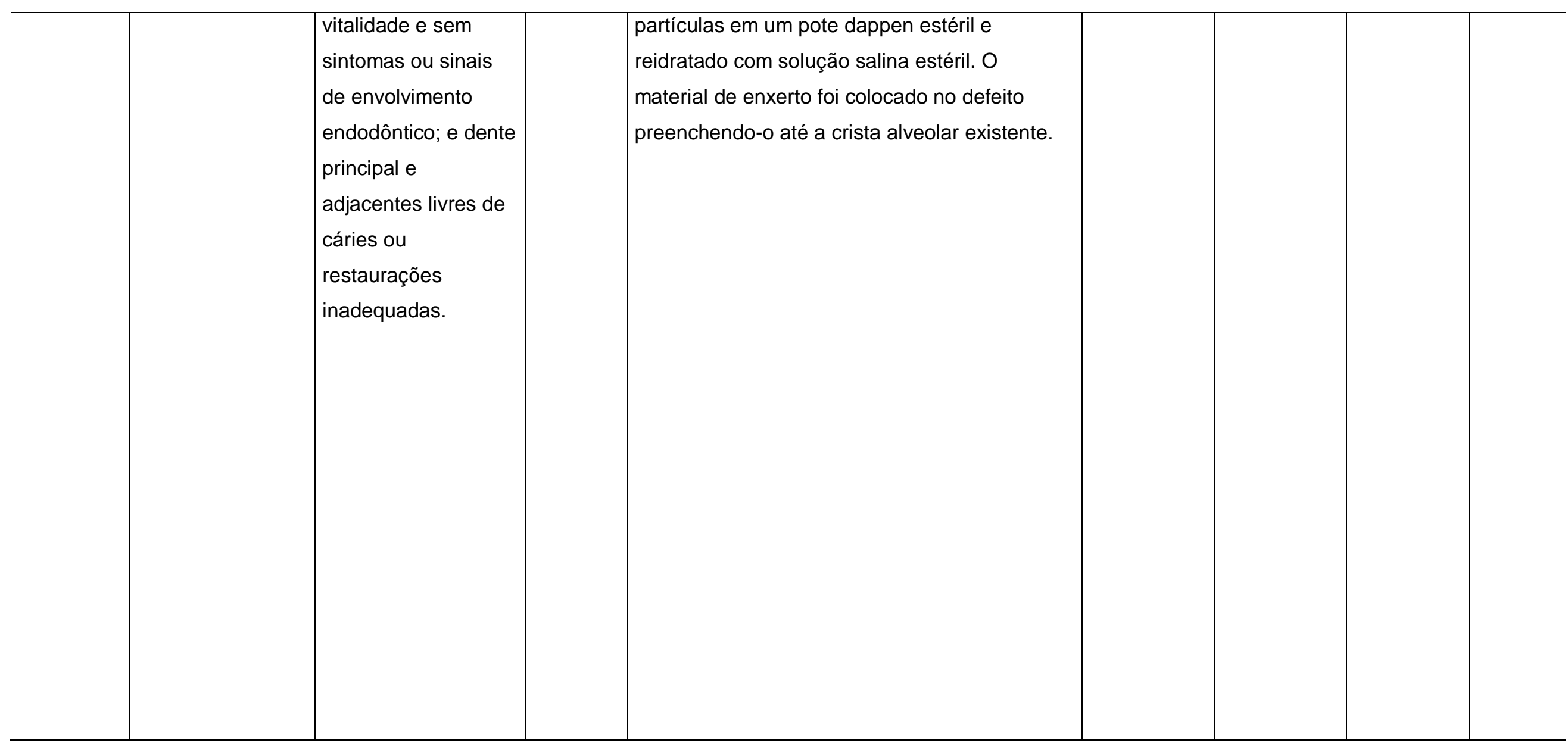




\section{RECIMA21 - REVISTA CIENTÍFICA MULTIDISCIPLINAR}

FIBRINA RICA EM PLAQUETAS NO TRATAMENTO REGENERATIVO ÓSSEO PERIODONTAL: UMA REVISÃO DE ESCOPO Kamily Alves de Carvalho Chiconelo Sanches, Laryssa Macedo de Oliveira, Magda Feres, uliana Ferreira, Dimorvan Bordin, Belén Retamal-Valdes

\begin{tabular}{|c|c|c|c|c|c|c|c|c|}
\hline $\begin{array}{l}\text { Chadwick } \\
\text { et al (17) }\end{array}$ & $\begin{array}{l}\text { Defeitos de } 2 \\
\text { paredes: potencial } \\
\text { de contenção } \\
\text { moderado; } \\
\text { Defeitos de } 1 \\
\text { parede: potencial } \\
\text { de contenção } \\
\text { relativamente } \\
\text { pobre (incluíam } \\
\text { defeitos de } 1 \\
\text { parede, 1,2, 1,3 e } \\
\text { 1,2,3 paredes) }\end{array}$ & $\begin{array}{l}\text { Os critérios de } \\
\text { inclusão são: idade } \\
\text { entre } 18 \text { e } 89 \text { anos; } \\
\text { periodontite crônica } \\
\text { requerendo } \\
\text { intervenção cirúrgica } \\
\text { para tratamento de } \\
\text { defeito intraósseo } \\
\text { adjacente à dentes } \\
\text { naturais; capacidade } \\
\text { de consentir com o } \\
\text { tratamento; } \\
\text { disponibilidade para } \\
\text { múltiplos } \\
\text { acompanhamentos; } \\
\text { um ou mais defeitos } \\
\text { periodontais com PS } \\
\geq 6 \text { mm; defeito } \\
\text { radiográfico ósseo } \\
\text { vertical com } \\
\text { profundidade >3 mm }\end{array}$ & $\begin{array}{l}\text { Teste: } \\
\text { [PRF] } \\
\text { Controle: } \\
\text { [DFDBA] }\end{array}$ & $\begin{array}{l}\text { [PRF] A terapia cirúrgica foi realizada por } \\
\text { residentes no programa de pós-graduação em } \\
\text { periodontia da UTHSCSA sob supervisão direta } \\
\text { de um corpo docente certificado pelo Conselho. } \\
\text { As incisões intrasulculares foram feitas e os } \\
\text { retalhos mucoperiosteais foram rebatidos para } \\
\text { permitir o debridamento completo das } \\
\text { superfícies radiculares e do defeito intraósseo. } \\
\text { Após serem pressionadas em bandeja } \\
\text { perfurada para remoção do serum, as } \\
\text { membranas de PRF foram recortadas em } \\
\text { tamanhos apropriados para preenchimento dos } \\
\text { defeitos ósseos até margem mais coronal da } \\
\text { crista alveolar. } \\
\text { [DFDBA] Foi utilizado DFDBA hidratado em } \\
\text { solução salina estéril, seguido de leve } \\
\text { compressão para atingir o preenchimento do } \\
\text { defeito até a margem mais coronal da crista } \\
\text { alveolar. Todo o DFDBA usado neste estudo } \\
\text { veio de um único doador, um homem de } 42 \\
\text { anos, e foi processado para um tamanho de }\end{array}$ & $\begin{array}{l}\text { Teste: } \\
\text { [PRF] } 17 \\
\text { Controle: } \\
\text { [DFBDA] } 19 \\
\text { *exclusão } \\
\text { de } 5 \\
\text { pacientes do } \\
n^{\circ} \text { inicial }\end{array}$ & $\begin{array}{l}\text { JCE-BD- } \\
\text { cirúrgico } \\
\text { inicial/final } \\
\text { (mm) } \\
\text { Preenchime } \\
\text { nto ósseo- } \\
\text { cirúrgico } \\
\text { (mm) } \\
\text { JCE-BD- } \\
\text { radiográfico } \\
\text { inicial/final } \\
\text { (mm) } \\
\text { Preenchime } \\
\text { nto ósseo- } \\
\text { radiográfico } \\
\text { (mm) } \\
\text { CA-BD } \\
\text { inicial (mm) } \\
\text { JCE-CA } \\
\text { inicial (mm) } \\
\text { Largura do }\end{array}$ & $\begin{array}{l}\text { PS } \\
\text { inicial/final } \\
(\mathrm{mm}) \\
\triangle \mathrm{RPS} \\
(\mathrm{mm}) \\
\mathrm{RG} \\
\text { inicial/final } \\
(\mathrm{mm}) \\
\triangle \mathrm{RG} \\
(\mathrm{mm}) \\
\mathrm{NCl} \\
\text { inicial/final } \\
(\mathrm{mm}) \\
\triangle \mathrm{NCl} \\
(\mathrm{mm})\end{array}$ & 6 meses \\
\hline
\end{tabular}




\section{RECIMA21 - REVISTA CIENTÍFICA MULTIDISCIPLINAR}

FIBRINA RICA EM PLAQUETAS NO TRATAMENTO REGENERATIVO ÓSSEO PERIODONTAL: UMA REVISÃO DE ESCOPO Kamily Alves de Carvalho Chiconelo Sanches, Laryssa Macedo de Oliveira, Magda Feres, uliana Ferreira, Dimorvan Bordin, Belén Retamal-Valdes

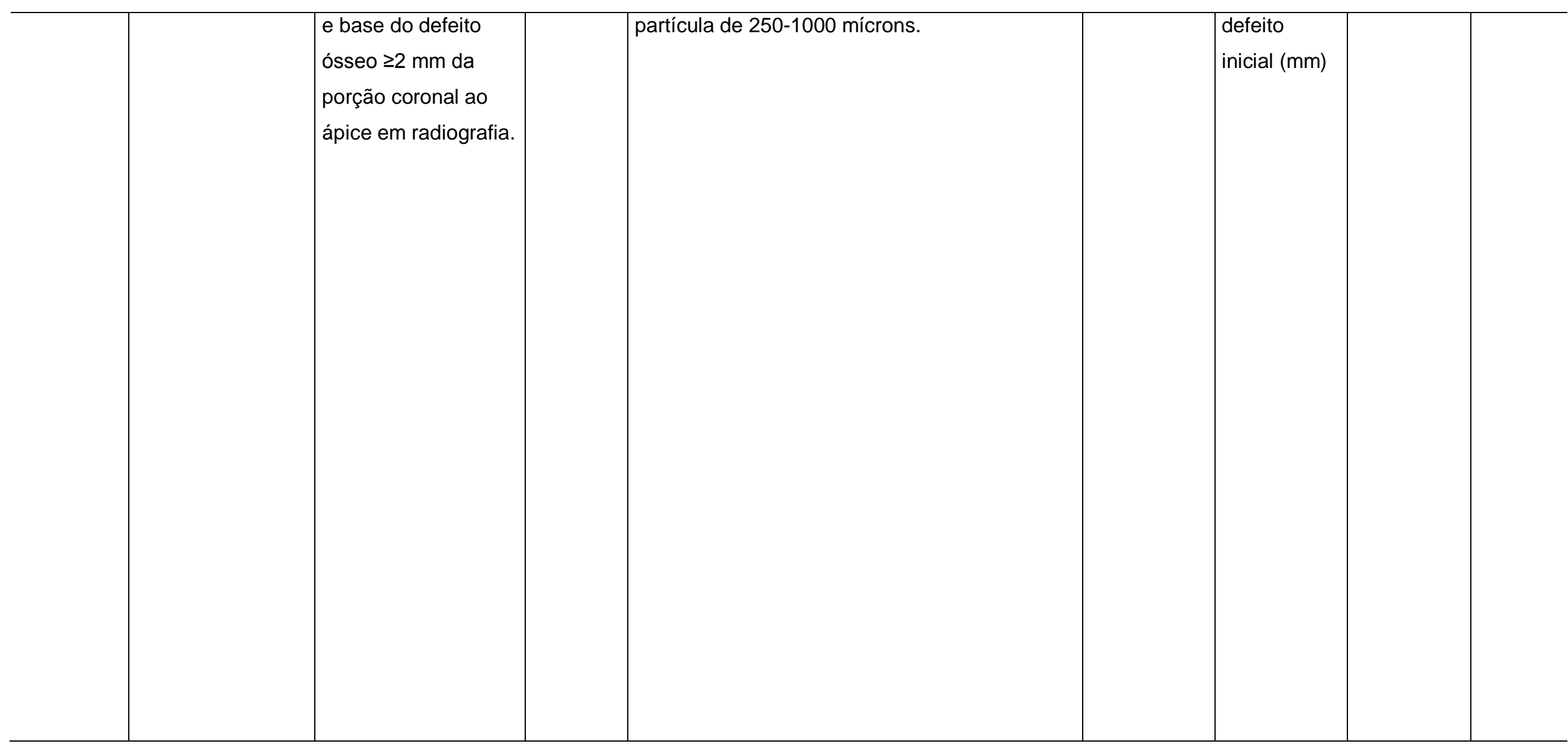




\section{RECIMA21 - REVISTA CIENTÍFICA MULTIDISCIPLINAR}

FIBRINA RICA EM PLAQUETAS NO TRATAMENTO REGENERATIVO ÓSSEO PERIODONTAL: UMA REVISÃO DE ESCOPO Kamily Alves de Carvalho Chiconelo Sanches, Laryssa Macedo de Oliveira, Magda Feres, uliana Ferreira, Dimorvan Bordin, Belén Retamal-Valdes

\begin{tabular}{|c|c|c|c|c|c|c|c|c|}
\hline $\begin{array}{l}\text { Agarwal et } \\
\text { al (14) }\end{array}$ & $\begin{array}{l}\text { Defeitos ósseos } \\
\text { de duas ou três } \\
\text { paredes com PS } \geq \\
6 \mathrm{~mm} \\
\text { assintomáticos em } \\
\text { dentes } \\
\text { posteriores. }\end{array}$ & $\begin{array}{l}\text { Os critérios de } \\
\text { inclusão foram: } \\
\text { defeitos intraósseos } \\
\text { com duas ou três } \\
\text { paredes; } \\
\text { interproximais } \\
\text { pareados com PS } \geq \\
6 \text { mm quando } \\
\text { avaliados } 8 \text { semanas } \\
\text { após a terapia inicial } \\
\text { com profundidade do } \\
\text { defeito } \geq 4 \text { mm; } \\
\text { assintomáticos; em } \\
\text { molares posteriores; } \\
\text { índice de placa dos } \\
\text { dentes tratados } \leq \\
1 \text { mm após } \\
\text { reavaliação da } \\
\text { terapia inicial; } \\
\text { evidência } \\
\text { radiográfica da }\end{array}$ & $\begin{array}{l}\text { Teste: } \\
\text { [DFDBA+ } \\
\text { PRF] } \\
\text { Controle: } \\
\text { [DFDBA+ } \\
\text { solução } \\
\text { salina] }\end{array}$ & $\begin{array}{l}\text { [DFDBA+PRF ou DFDBA+solução salina] Após } \\
\text { a administração de anestesia local, foram feitas } \\
\text { incisões sulculares bucais e linguais e os } \\
\text { retalhos mucoperiosteais foram elevados. Foi } \\
\text { tomado cuidado para preservar o máximo } \\
\text { possível de tecido mole interproximal. Foi } \\
\text { realizado debridamento completo dos defeitos, } \\
\text { bem como raspagem e alisamento radicular } \\
\text { para garantir o aplainamento radicular com o } \\
\text { uso de aparelho de ultrassom e instrumentos } \\
\text { manuais. DFDBA (LifeNet Health, Virginia } \\
\text { Beach, VA) foi misturado com PRF ou solução } \\
\text { salina na proporção de } 1: 1 \text { (v/v) para } \\
\text { preenchimento no mesmo nível que a parede } \\
\text { de defeito ósseo, na porção mais coronal } \\
\text { existente, de acordo com o grupo tratado. Foi } \\
\text { tomado cuidado para não sobrecarregar os } \\
\text { defeitos. Uma membrana de PRF comprimida } \\
\text { foi recortada e adaptada sobre os defeitos } \\
\text { enxertados em ambos os grupos. As } \\
\text { membranas foram estendidas sobre a periferia }\end{array}$ & $\begin{array}{l}\text { Teste: } \\
\text { [DFDBA+PR } \\
\text { F] } 15 \\
\text { Controle: } \\
\text { [DFDBA+sol } \\
\text { ução salina] } \\
15 \\
\text { *2 pacientes } \\
\text { perdidos do } \\
\text { n inicial }\end{array}$ & $\mathrm{NCl}(\mathrm{mm})$ & $\begin{array}{l}\text { PS (mm) } \\
\text { Índice de } \\
\text { placa } \\
\text { (score) } \\
\text { JCE-BD } \\
\text { (mm) } \\
\text { ISSm } \\
\text { (score) }\end{array}$ & $\begin{array}{l}12 \\
\text { meses }\end{array}$ \\
\hline
\end{tabular}




\section{RECIMA21 - REVISTA CIENTÍFICA MULTIDISCIPLINAR}

FIBRINA RICA EM PLAQUETAS NO TRATAMENTO REGENERATIVO ÓSSEO PERIODONTAL: UMA REVISÃO DE ESCOPO Kamily Alves de Carvalho Chiconelo Sanches, Laryssa Macedo de Oliveira, Magda Feres, uliana Ferreira, Dimorvan Bordin, Belén Retamal-Valdes

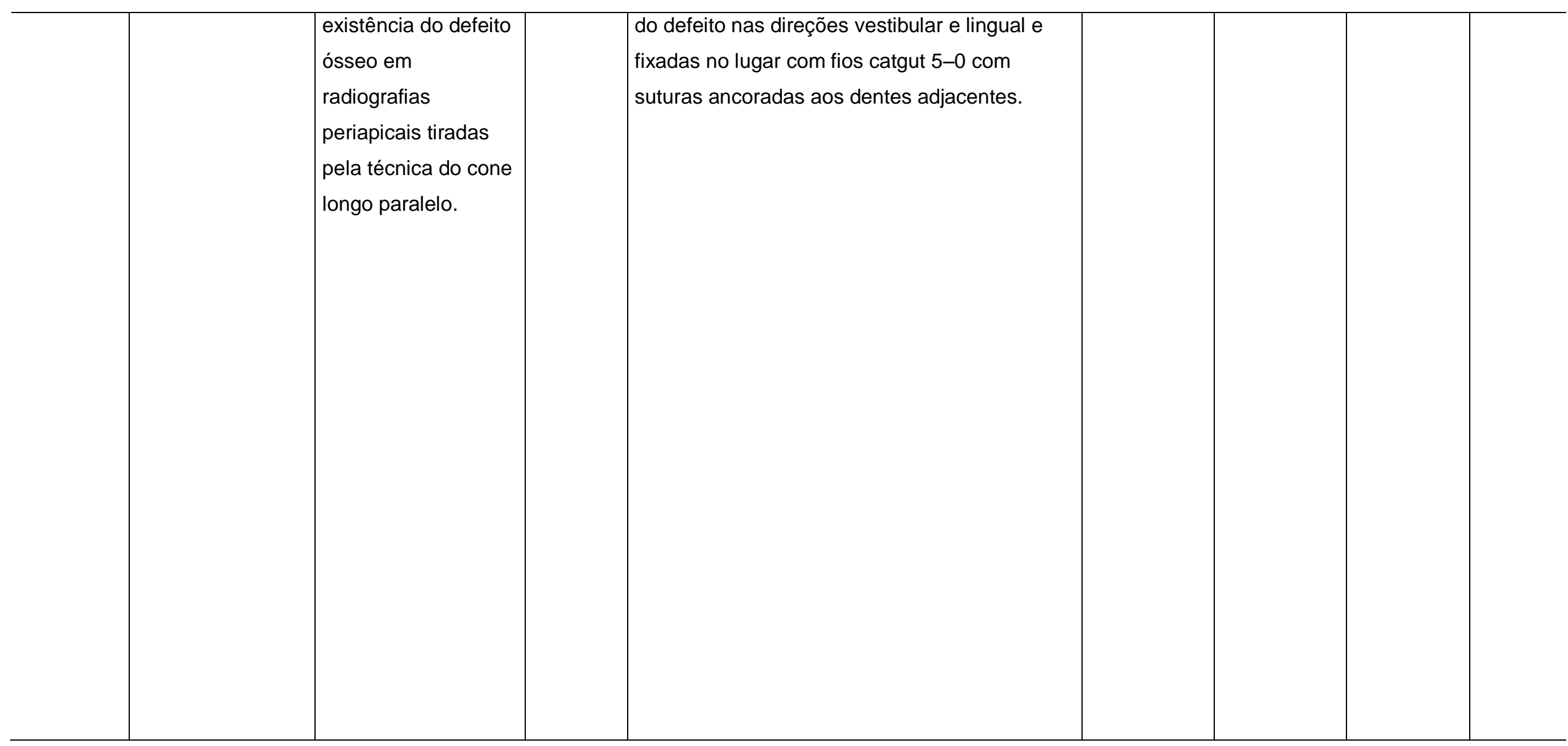




\section{RECIMA21 - REVISTA CIENTÍFICA MULTIDISCIPLINAR}

FIBRINA RICA EM PLAQUETAS NO TRATAMENTO REGENERATIVO ÓSSEO PERIODONTAL: UMA REVISÃO DE ESCOPO Kamily Alves de Carvalho Chiconelo Sanches, Laryssa Macedo de Oliveira, Magda Feres, uliana Ferreira, Dimorvan Bordin, Belén Retamal-Valdes

\begin{tabular}{|c|c|c|c|c|c|c|c|}
\hline $\begin{array}{l}\text { Lekovic et } \\
\text { al (13) }\end{array}$ & $\begin{array}{l}\text { Dois defeitos } \\
\text { intraósseos } \\
\text { similares com } \\
\text { duas ou três } \\
\text { paredes com PS } \geq \\
6 \mathrm{~mm} .\end{array}$ & $\begin{array}{l}\text { Os critérios de } \\
\text { inclusão foram: } \\
\text { presença de dois } \\
\text { defeitos intraósseos } \\
\text { interproximais } \\
\text { similares com PS } \geq 6 \\
\text { mm quando } \\
\text { avaliados } 6 \text { semanas } \\
\text { depois da terapia } \\
\text { inicial; apenas } \\
\text { dentes vitais } \\
\text { segundo o teste frio; } \\
\text { índices gengivais e } \\
\text { de placa } \leq 1 ; \\
\text { evidência } \\
\text { radiográfica da } \\
\text { existência do defeito } \\
\text { ósseo em } \\
\text { radiografias } \\
\text { periapicais tiradas } \\
\text { pela técnica do cone }\end{array}$ & $\begin{array}{l}\text { Teste: } \\
\text { [PRF+BP } \\
\text { BM] } \\
\text { Controle: } \\
{[\mathrm{PRF}]}\end{array}$ & $\begin{array}{l}\text { [PRF+BPBM] O procedimento cirúrgico foi } \\
\text { realizado sob infiltração local de lidocaína a } 2 \% \\
\text { contendo epinefrina na concentração de } \\
\text { 1:100.000. Incisões sulculares vestibulares e } \\
\text { linguais foram feitas e retalhos mucoperiosteais } \\
\text { elevados. No grupo PRF-BPBM, grânulos de } \\
\text { BPBM esponjosos (Bio-Oss; Geistlich AG, } \\
\text { Wolhusen, Suíça) com tamanhos de partícula } \\
\text { de 0,25-1,0 mm foram misturados com PRF } \\
\text { que foi cortado em pedaços de cerca de 0,5 } \\
\text { mm a uma proporção de } 1: 1 \text { (v/v). A mistura } \\
\text { PRF-BPBM foi levada ao defeito e condensada } \\
\text { com condensadores de amálgama ao nível das } \\
\text { paredes ósseas circundantes. Uma membrana } \\
\text { de PRF comprimida foi aparada e adaptada } \\
\text { sobre o defeito enxertado. } \\
\text { [PRF] Defeitos no grupo PRF foram } \\
\text { preenchidos apenas com PRF picado. Uma } \\
\text { membrana de PRF comprimida foi adaptada } \\
\text { sobre o defeito preenchido com PRF picado da } \\
\text { mesma maneira descrita para o grupo PRF- }\end{array}$ & $\begin{array}{l}17 \\
\text { *não foi } \\
\text { especificado } \\
\text { a } \\
\text { quantidade } \\
\text { em cada } \\
\text { grupo }\end{array}$ & $\begin{array}{l}\text { Sangramento } \\
\text { gengival } \\
\text { (score) } \\
\mathrm{PS}(\mathrm{mm}) \\
\mathrm{NCl}(\mathrm{mm}) \\
\mathrm{RG}(\mathrm{mm}) \\
\text { Preenchimento } \\
\text { do defeito (mm) } \\
\text { Média de } \\
\text { reabsorção } \\
\text { (mm) } \\
\text { Índice de placa } \\
\text { (score) }\end{array}$ & $1 / 2 / 3 / 6$ meses \\
\hline
\end{tabular}




\section{RECIMA21 - REVISTA CIENTÍFICA MULTIDISCIPLINAR}

FIBRINA RICA EM PLAQUETAS NO TRATAMENTO REGENERATIVO ÓSSEO PERIODONTAL: UMA REVISÃO DE ESCOPO Kamily Alves de Carvalho Chiconelo Sanches, Laryssa Macedo de Oliveira, Magda Feres, Juliana Ferreira, Dimorvan Bordin, Belén Retamal-Valdes

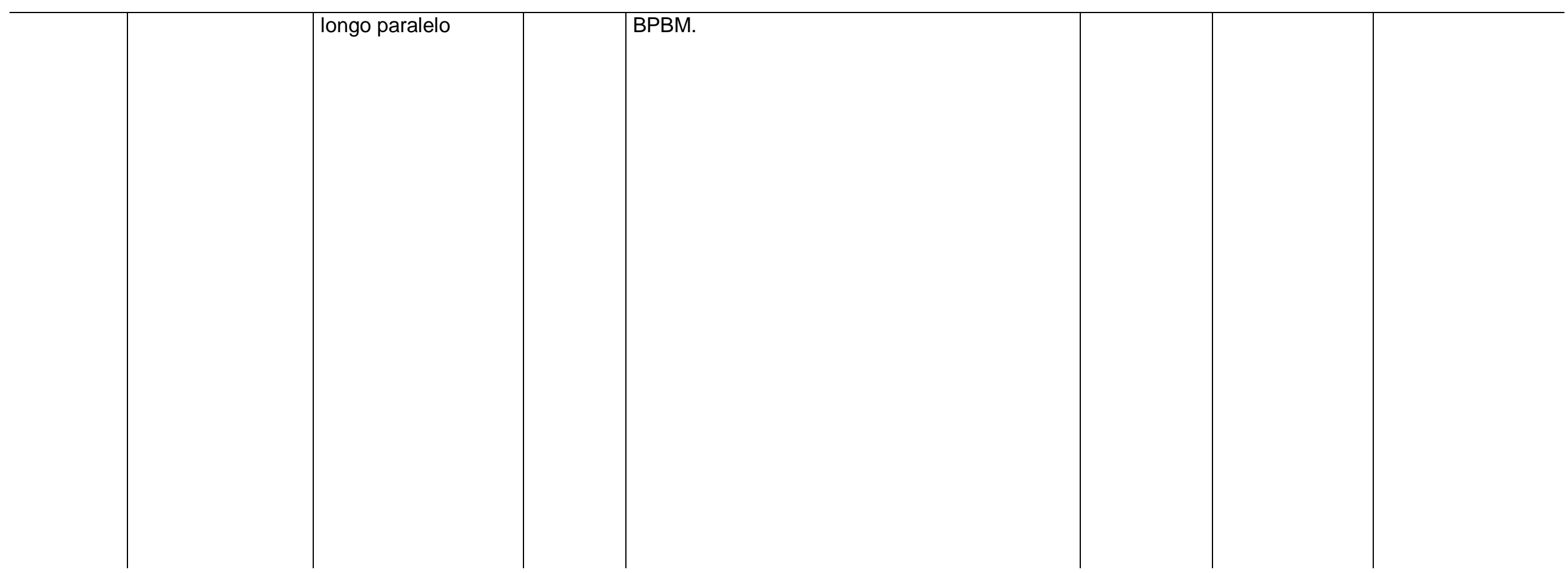




\section{RECIMA21 - REVISTA CIENTÍFICA MULTIDISCIPLINAR}

FIBRINA RICA EM PLAQUETAS NO TRATAMENTO REGENERATIVO ÓSSEO PERIODONTAL: UMA REVISÃO DE ESCOPO Kamily Alves de Carvalho Chiconelo Sanches, Laryssa Macedo de Oliveira, Magda Feres, Juliana Ferreira, Dimorvan Bordin, Belén Retamal-Valdes

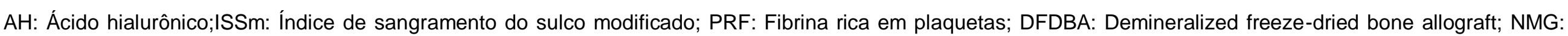

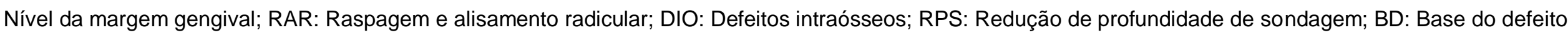

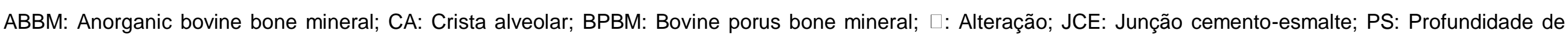
sondagem; RG: Retração gengival; NCl: Nível clínico de inserção 


\section{RECIMA21 - REVISTA CIENTÍFICA MULTIDISCIPLINAR}

FIBRINA RICA EM PLAQUETAS NO TRATAMENTO REGENERATIVO ÓSSEO PERIODONTAL: UMA REVISÃO DE ESCOPO Kamily Alves de Carvalho Chiconelo Sanches, Laryssa Macedo de Oliveira, Magda Feres, Juliana Ferreira, Dimorvan Bordin, Belén Retamal-Valdes

Tabela 4. Principais resultados clínicos dos artigos incluídos

\begin{tabular}{|c|c|c|c|c|c|c|c|}
\hline Referência & Grupos de & Idade & Gênero & Variáı & rimária & Variáa & el secundária \\
\hline $\begin{array}{l}\text { Pradeep et } \\
\text { al (7) }\end{array}$ & $\begin{array}{l}\text { Teste: } \\
{[\mathrm{PRF}]} \\
{[\mathrm{PRF}+\mathrm{HA}]} \\
\text { Controle: } \\
{[\mathrm{RAR}]}\end{array}$ & $\begin{array}{l}\text { Média: } \\
39.7 \\
\text { anos }\end{array}$ & $34 \mathrm{H} / 28 \mathrm{M}$ & $\begin{array}{l}\text { BASELINE } \\
\text { Teste: } \\
\text { [PRF] } \\
\text { NMG: } 1.63 \pm 0.49 \mathrm{~mm} \\
\text { Profundidade DIO: } \\
5.63 \pm 1.16 \mathrm{~mm} \\
\text { [PRF+HA] } \\
\text { NMG: } 1.77 \pm 0.43 \mathrm{~mm} \\
\text { Profundidade DIO: } \\
6.03 \pm 1.16 \mathrm{~mm} \\
\text { Controle: } \\
\text { [RAR] } \\
\text { NMG: } 1.77 \pm 0.43 \mathrm{~mm} \\
\text { Profundidade DIO: } \\
5.80 \pm 0.81 \mathrm{~mm}\end{array}$ & $\begin{array}{l}9 \text { MESES } \\
\text { Teste: } \\
\text { [PRF] } \\
\text { NMG: } 1.17 \pm 0.46 \mathrm{~mm} \\
\text { Profundidade DIO: } \\
2.43 \pm 0.68 \mathrm{~mm} \\
\text { [PRF+HA] } \\
\text { NMG: } 1.10 \pm 0.31 \mathrm{~mm} \\
\text { Profundidade DIO: } \\
2.17 \pm 0.99 \mathrm{~mm} \\
\text { Controle: } \\
\text { [RAR] } \\
\text { NMG: } 1.93 \pm 0.25 \mathrm{~mm} \\
\text { Profundidade DIO: } \\
4.87 \pm 1.04 \mathrm{~mm}\end{array}$ & 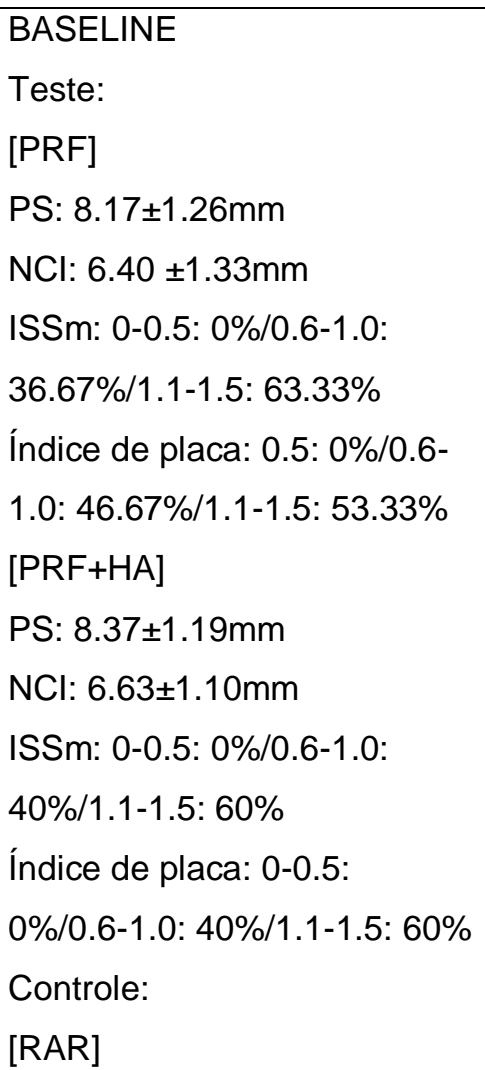 & $\begin{array}{l}9 \text { MESES } \\
\text { Teste: } \\
\text { [PRF] } \\
\text { PS: } 4.27 \pm 0.69 \mathrm{~mm} \\
\text { NCI: } 3.37 \pm 0.56 \mathrm{~mm} \\
\text { ISSm: 0-0.5: 70\%/0.6-1.0: 30\%/1.1- } \\
\text { 1.5:0\% } \\
\text { Índice de placa: 0.5: 73.33\%/0.6-1.0: } \\
\text { 26.67\%/1.1-1.5: 0\% } \\
\text { PS: } 4.10 \pm 0.85 \mathrm{~mm}+\mathrm{HA}] \\
\text { NCI: } 2.97 \pm 0.93 \mathrm{~mm} \\
\text { ISSm: 0-0.5: } 80 \% / 0.6-1.0: 20 \% / 1.1- \\
\text { 1.5: } 0 \% \\
\text { Índice de placa:0-0.5: } 80 \% 0.6-1.0: \\
20 \% / 1.1-1.5: 0 \% \\
\text { Controle: } \\
\text { [RAR] } \\
\text { PS: } 5.07 \pm 0.74 \mathrm{~mm}\end{array}$ \\
\hline
\end{tabular}




\section{RECIMA21 - REVISTA CIENTÍFICA MULTIDISCIPLINAR}

FIBRINA RICA EM PLAQUETAS NO TRATAMENTO REGENERATIVO ÓSSEO PERIODONTAL: UMA REVISÃO DE ESCOPO Kamily Alves de Carvalho Chiconelo Sanches, Laryssa Macedo de Oliveira, Magda Feres, Juliana Ferreira, Dimorvan Bordin, Belén Retamal-Valdes

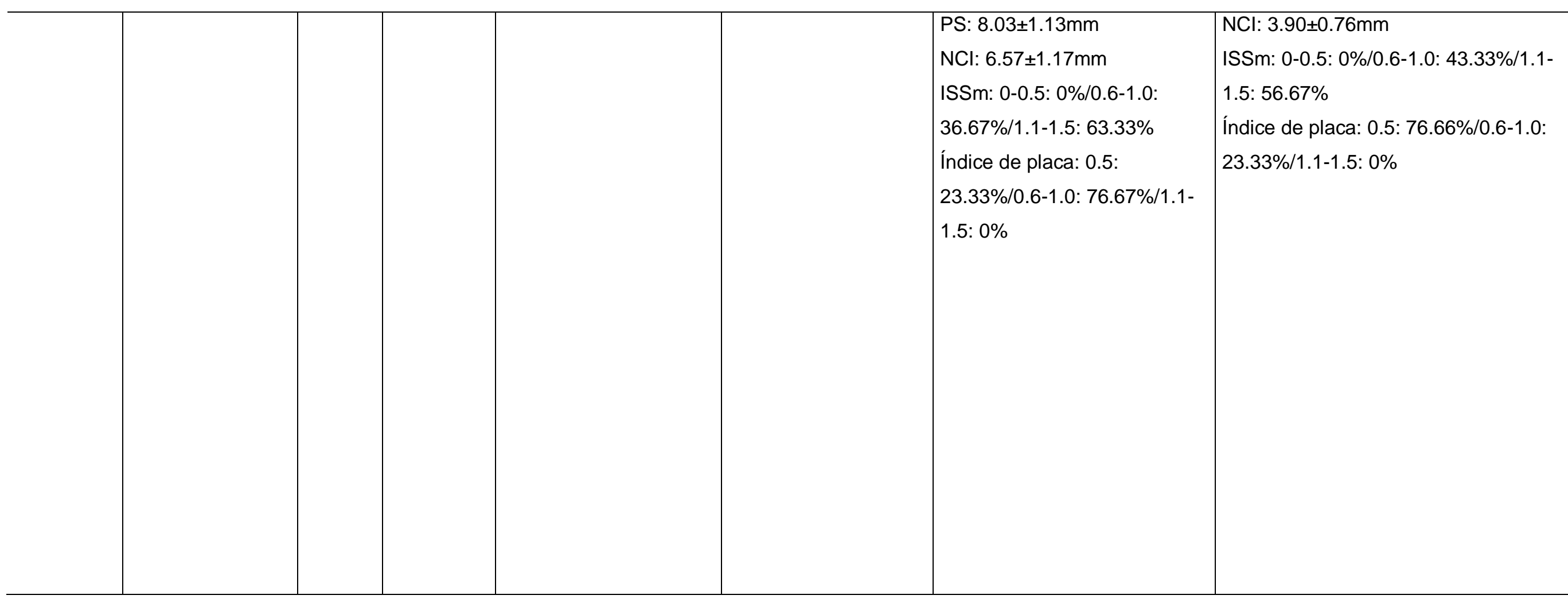




\section{RECIMA21 - REVISTA CIENTÍFICA MULTIDISCIPLINAR}

FIBRINA RICA EM PLAQUETAS NO TRATAMENTO REGENERATIVO ÓSSEO PERIODONTAL: UMA REVISÃO DE ESCOPO Kamily Alves de Carvalho Chiconelo Sanches, Laryssa Macedo de Oliveira, Magda Feres, uliana Ferreira, Dimorvan Bordin, Belén Retamal-Valdes

\begin{tabular}{|c|c|c|c|c|c|c|c|}
\hline $\begin{array}{l}\text { Sezgin et } \\
\text { al (16) }\end{array}$ & $\begin{array}{l}\text { Teste: } \\
\text { [PRF+ABBM] } \\
\text { Controle: } \\
\text { [ABBM] }\end{array}$ & $\begin{array}{l}38 \text { a } 61 \\
\text { anos }\end{array}$ & $\begin{array}{l}8 \mathrm{H} / 7 \mathrm{M} \\
{ }^{*} \text { exclusão } \\
\text { de } 15 \\
\text { pacientes } \\
\text { do } n^{\circ} \\
\text { inicial }\end{array}$ & $\begin{array}{l}\text { BASELINE } \\
\text { Teste: } \\
\text { [PRF+ABBM] } \\
\text { PS: } 7.46 \pm 1.19 \mathrm{~mm} \\
\text { RG: } 0.87 \pm 0.91 \mathrm{~mm} \\
\text { NCl: } 8.33 \pm 1.76 \mathrm{~mm} \\
\text { Perda óssea vertical: } \\
8.44 \pm 2.13 \mathrm{~mm} \\
\text { Profundidade do } \\
\text { defeito: } 4.33 \pm 0.93 \mathrm{~mm} \\
\text { Angulação do defeito: } \\
37.87 \pm 5.25 \circ \\
\text { Controle: } \\
\text { [ABBM] } \\
\text { PS: } 7.07 \pm 1.03 \mathrm{~mm} \\
\text { RG: } 0.66 \pm 0.72 \mathrm{~mm} \\
\text { NCl: } 7.73 \pm 1.16 \mathrm{~mm} \\
\text { Perda óssea vertical: } 8 \\
\pm 1.71 \mathrm{~mm} \\
\text { Profundidade do } \\
\text { defeito: } 3.64 \pm 0.93 \mathrm{~mm}\end{array}$ & $\begin{array}{l}6 \text { MESES } \\
\text { Teste: } \\
\text { [PRF+ABBM] } \\
\text { PS: } 2.53 \pm 0.74 \mathrm{~mm} \\
\text { RG:1.33 } \pm 0.82 \mathrm{~mm} \\
\text { NCI: } 3.86 \pm 1.19 \mathrm{~mm} \\
\text { Perda óssea vertical: } \\
4.08 \pm 1.09 \mathrm{~mm} \\
\text { Profundidade do } \\
\text { defeito: } 1.78 \pm \\
0.39 \mathrm{~mm} \\
\text { Angulação do defeito: } \\
51.15 \pm 4.02 \circ \\
\text { Controle: } \\
\text { [ABBM] } \\
\text { PS: } 2.86 \pm 1.12 \mathrm{~mm} \\
\text { RG: } 1.60 \pm 0.63 \mathrm{~mm} \\
\text { NCl: } 4.46 \pm 1.35 \mathrm{~mm} \\
\text { Perda óssea vertical: } \\
4.06 \pm 0.91 \mathrm{~mm} \\
\text { Profundidade do }\end{array}$ & $\begin{array}{l}\text { BASELINE } \\
\text { Teste: } \\
\text { [PRF+ABBM] } \\
\text { Índice de placa: } 0.07 \pm 0.25 \\
\text { Índice gengival: } 0.93 \pm 0.59 \\
\text { Controle: } \\
\text { [ABBM] } \\
\text { Índice de placa: } 0.13 \pm 0.35 \\
\text { Índice gengival: } 0.94 \pm 0.01\end{array}$ & $\begin{array}{l}6 \text { MESES } \\
\text { Teste: } \\
\text { [PRF+ABBM] } \\
\text { Índice de placa: } 0.13 \pm 0.35 \\
\text { Índice gengival: } 0.27 \pm 0.46 \\
\text { Controle: } \\
\text { [ABBM] } \\
\text { Índice de placa: } 0.13 \pm 0.35 \\
\text { Índice gengival: } 0.28 \pm 0.01\end{array}$ \\
\hline
\end{tabular}




\section{RECIMA21 - REVISTA CIENTÍFICA MULTIDISCIPLINAR}

FIBRINA RICA EM PLAQUETAS NO TRATAMENTO REGENERATIVO ÓSSEO PERIODONTAL: UMA REVISÃO DE ESCOPO Kamily Alves de Carvalho Chiconelo Sanches, Laryssa Macedo de Oliveira, Magda Feres, uliana Ferreira, Dimorvan Bordin, Belén Retamal-Valdes

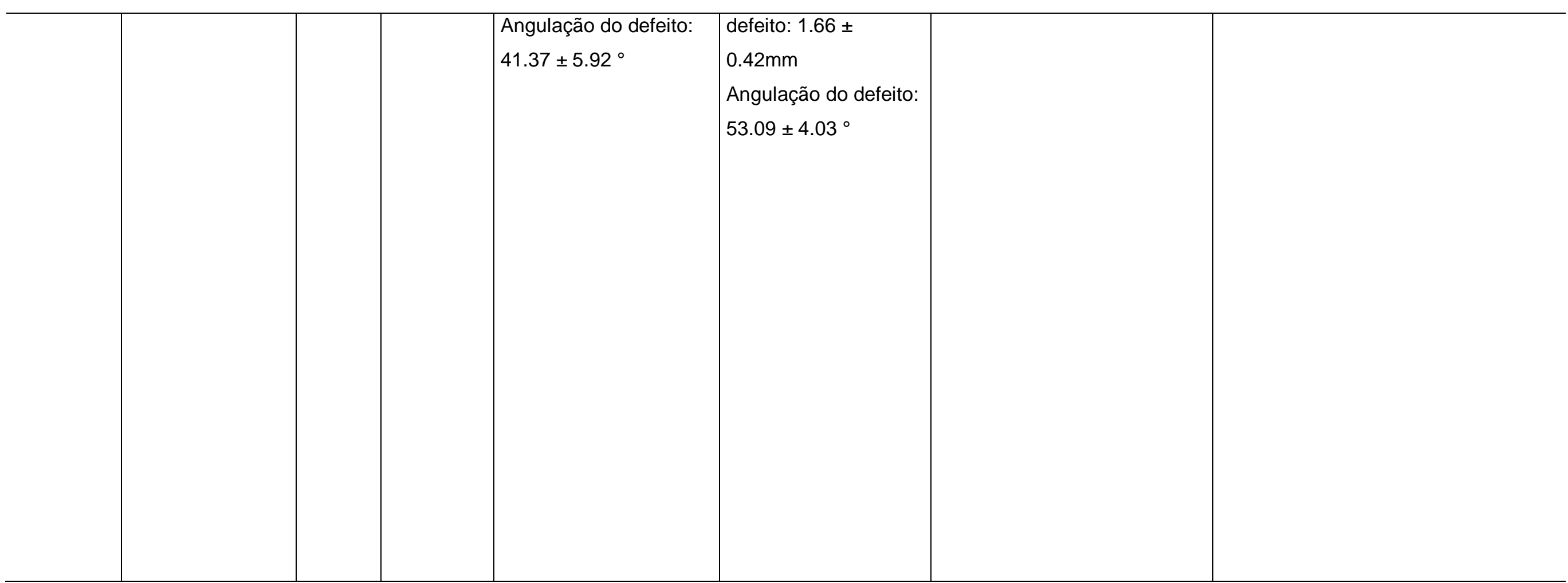




\section{RECIMA21 - REVISTA CIENTÍFICA MULTIDISCIPLINAR}

FIBRINA RICA EM PLAQUETAS NO TRATAMENTO REGENERATIVO ÓSSEO PERIODONTAL: UMA REVISÃO DE ESCOPO Kamily Alves de Carvalho Chiconelo Sanches, Laryssa Macedo de Oliveira, Magda Feres, uliana Ferreira, Dimorvan Bordin, Belén Retamal-Valdes

\begin{tabular}{|c|c|c|c|c|c|c|c|}
\hline $\begin{array}{l}\text { Chadwick } \\
\text { et al (17) }\end{array}$ & $\begin{array}{l}\text { Teste: } \\
\text { [PRF] } \\
\text { Controle: } \\
\text { [DFBDA] }\end{array}$ & $\begin{array}{l}\text { Média: } \\
54.9 \\
\text { anos }\end{array}$ & $\begin{array}{l}20 \mathrm{M} / 6 \mathrm{H} \\
\text { *exclusão } \\
\text { de } 5 \\
\text { pacientes } \\
\text { do } n^{\circ} \\
\text { inicial }\end{array}$ & 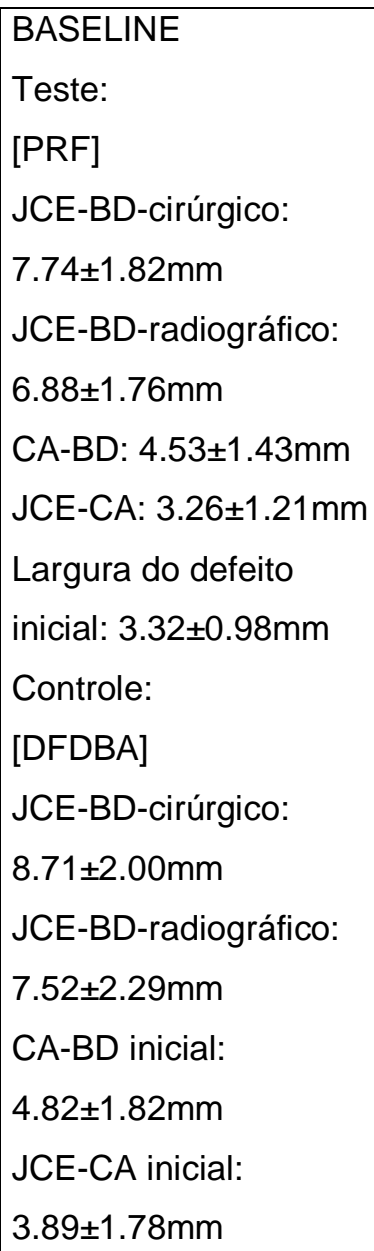 & 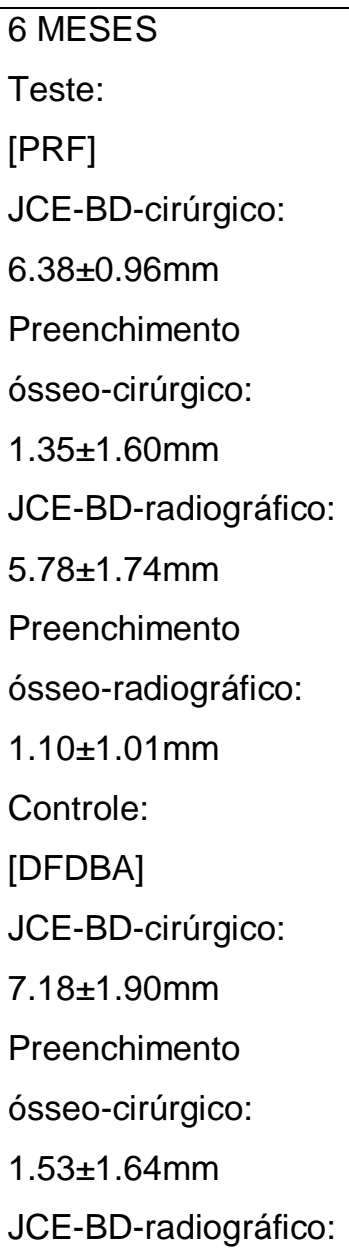 & $\begin{array}{l}\text { BASELINE } \\
\text { Teste: } \\
\text { [PRF] } \\
\text { PS: } 6.91 \pm 1.15 \mathrm{~mm} \\
\text { RG: }-0.56 \pm 1.04 \mathrm{~mm} \\
\text { NCI: } 6.32 \pm 1.07 \mathrm{~mm} \\
\text { Controle: } \\
\text { [DFDBA] } \\
\text { PS: } 6.82 \pm 0.89 \mathrm{~mm} \\
\text { RG: } 0.24 \pm 1.68 \mathrm{~mm} \\
\text { NCI: } 7.05 \pm 1.99 \mathrm{~mm}\end{array}$ & $\begin{array}{l}6 \mathrm{MESES} \\
\text { Teste: } \\
\text { [PRF] } \\
\text { PS: } 4.79 \pm 0.97 \mathrm{~mm} \\
\square \text { RPS: } 2.12 \pm 1.41 \mathrm{~mm} \\
\text { RG: } 0.50 \pm 1.47 \\
\square \mathrm{RG}: 1.06 \pm 1.18 \mathrm{~mm} \\
\text { NCI: } 5.29 \pm 1.09 \mathrm{~mm} \\
\square \mathrm{NCl}: 1.03 \pm 0.86 \mathrm{~mm} \\
\text { Controle: } \\
\text { [DFDBA] } \\
\text { PS: } 4.82 \pm 1.39 \mathrm{~mm} \\
\square \text { RPS: } 2.00 \pm 1.37 \mathrm{~mm} \\
\text { RG: } 1.08 \pm 1.77 \mathrm{~mm} \\
\square R G: 0.84 \pm 0.88 \mathrm{~mm} \\
\text { NCI: } 5.89 \pm 2.23 \mathrm{~mm} \\
\square \mathrm{NCl}: 1.16 \pm 1.33 \mathrm{~mm}\end{array}$ \\
\hline
\end{tabular}




\section{RECIMA21 - REVISTA CIENTÍFICA MULTIDISCIPLINAR}

FIBRINA RICA EM PLAQUETAS NO TRATAMENTO REGENERATIVO ÓSSEO PERIODONTAL: UMA REVISÃO DE ESCOPO Kamily Alves de Carvalho Chiconelo Sanches, Laryssa Macedo de Oliveira, Magda Feres, uliana Ferreira, Dimorvan Bordin, Belén Retamal-Valdes

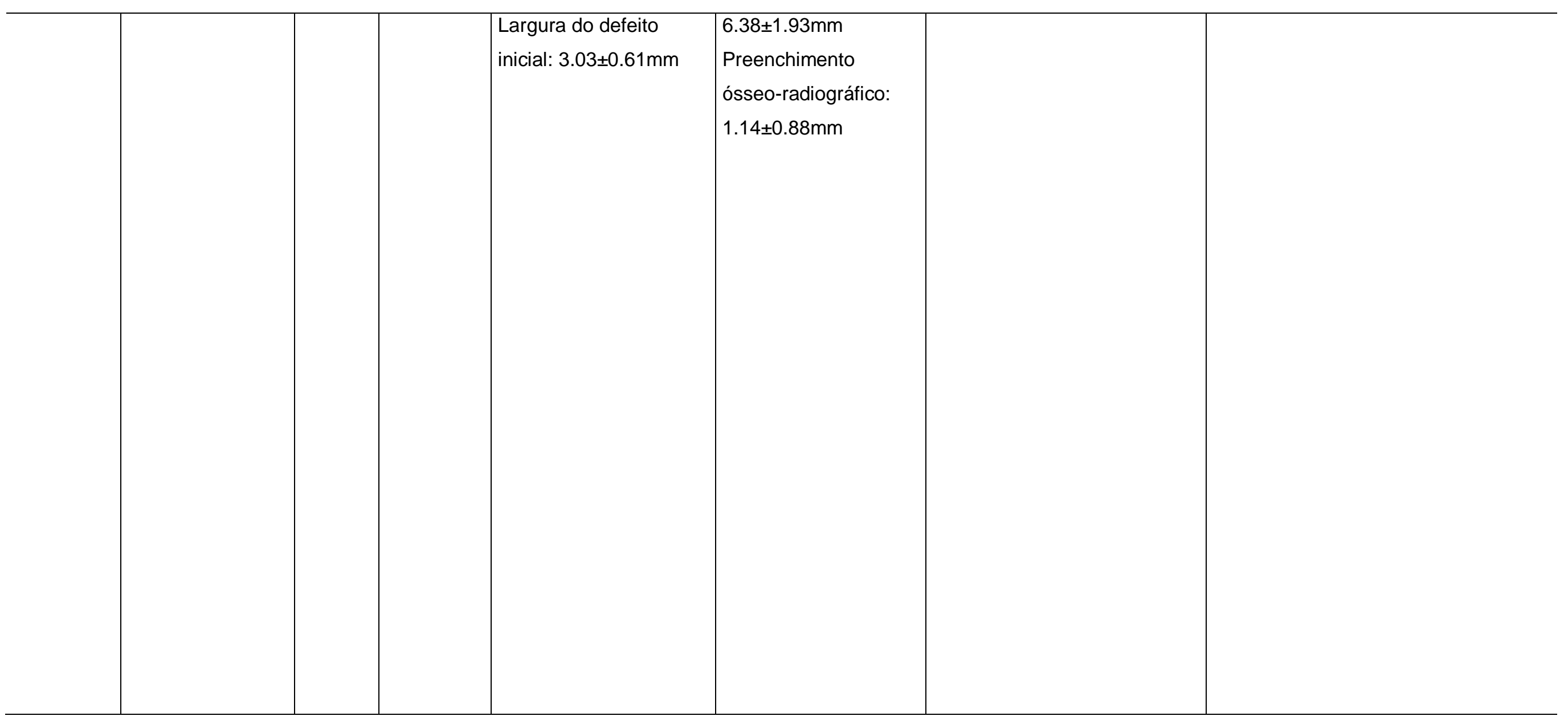




\section{RECIMA21 - REVISTA CIENTÍFICA MULTIDISCIPLINAR}

FIBRINA RICA EM PLAQUETAS NO TRATAMENTO REGENERATIVO ÓSSEO PERIODONTAL: UMA REVISÃO DE ESCOPO Kamily Alves de Carvalho Chiconelo Sanches, Laryssa Macedo de Oliveira, Magda Feres, uliana Ferreira, Dimorvan Bordin, Belén Retamal-Valdes

\begin{tabular}{|c|c|c|c|c|c|c|c|}
\hline $\begin{array}{l}\text { Agarwal et } \\
\text { al (14) }\end{array}$ & $\begin{array}{l}\text { Teste: } \\
\text { [DFDBA+PRF] } \\
\text { Controle: } \\
\text { [DFDBA+solução } \\
\text { salina] }\end{array}$ & $\begin{array}{l}\text { Média: } \\
52 \pm 7 \\
\text { anos }\end{array}$ & $\begin{array}{l}18 \mathrm{H} / 14 \mathrm{M} \\
{ }^{*} 2 \\
\text { pacientes } \\
\text { perdidos } \\
\text { do } \mathrm{n}^{\circ} \\
\text { inicial }\end{array}$ & $\begin{array}{l}\text { BASELINE } \\
\text { Teste: } \\
\text { [DFDBA+PRF] } \\
\mathrm{NCl}: 8.18 \pm 1.04 \mathrm{~mm} \\
\text { Controle: } \\
\text { [DFDBA+solução } \\
\text { salina] } \\
\mathrm{NCl}: 8.18 \pm 0.99 \mathrm{~mm}\end{array}$ & $\begin{array}{l}12 \text { MESES } \\
\text { Teste: } \\
\text { [DFDBA+PRF] } \\
\mathrm{NCl}: 4.45 \pm 0.80 \mathrm{~mm} \\
\text { Controle: } \\
\text { [DFDBA+solução } \\
\text { salina] } \\
\mathrm{NCl}: 5.57 \pm 1.17 \mathrm{~mm}\end{array}$ & $\begin{array}{l}\text { BASELINE } \\
\text { Teste: } \\
\text { [DFDBA+PRF] } \\
\text { PS: } 5.32 \pm 0.69 \mathrm{~mm} \\
\text { Índice de placa: } 0.63 \pm 0.20 \\
\text { JCE-BD: } 9.50 \pm 1.29 \mathrm{~mm} \\
\text { ISSm: } 1.01 \pm 0.27 \\
\text { Controle: } \\
\text { [DFDBA+solução salina] } \\
\text { PS: } 5.20 \pm 0.71 \mathrm{~mm} \\
\text { Índice de placa: } 0.62 \pm 0.22 \\
\text { JCE-BD: } 9.23 \pm 1.30 \mathrm{~mm} \\
\text { ISSm: } 0.95 \pm 0.27\end{array}$ & $\begin{array}{l}12 \text { MESES } \\
\text { Teste: } \\
\text { [DFDBA+PRF] } \\
\text { PS: } 1.58 \pm 0.49 \mathrm{~mm} \\
\text { Índice de placa: } 0.60 \pm 0.24 \\
\text { JCE-BD: } 6.00 \pm 1.15 \mathrm{~mm} \\
\text { ISSm: } 0.98 \pm 0.26 \text { ) } \\
\text { Controle: } \\
\text { [DFDBA+solução salina] } \\
\text { PS: } 2.45 \pm 0.63 \mathrm{~mm} \\
\text { Índice de placa: } 0.58 \pm 0.23 \\
\text { JCE-BD: } 6.75 \pm 1.28 \mathrm{~mm} \\
\text { ISSm: } 0.89 \pm 0.30\end{array}$ \\
\hline
\end{tabular}




\section{RECIMA21 - REVISTA CIENTÍFICA MULTIDISCIPLINAR}

FIBRINA RICA EM PLAQUETAS NO TRATAMENTO REGENERATIVO ÓSSEO PERIODONTAL: UMA REVISÃO DE ESCOPO Kamily Alves de Carvalho Chiconelo Sanches, Laryssa Macedo de Oliveira, Magda Feres, uliana Ferreira, Dimorvan Bordin, Belén Retamal-Valdes

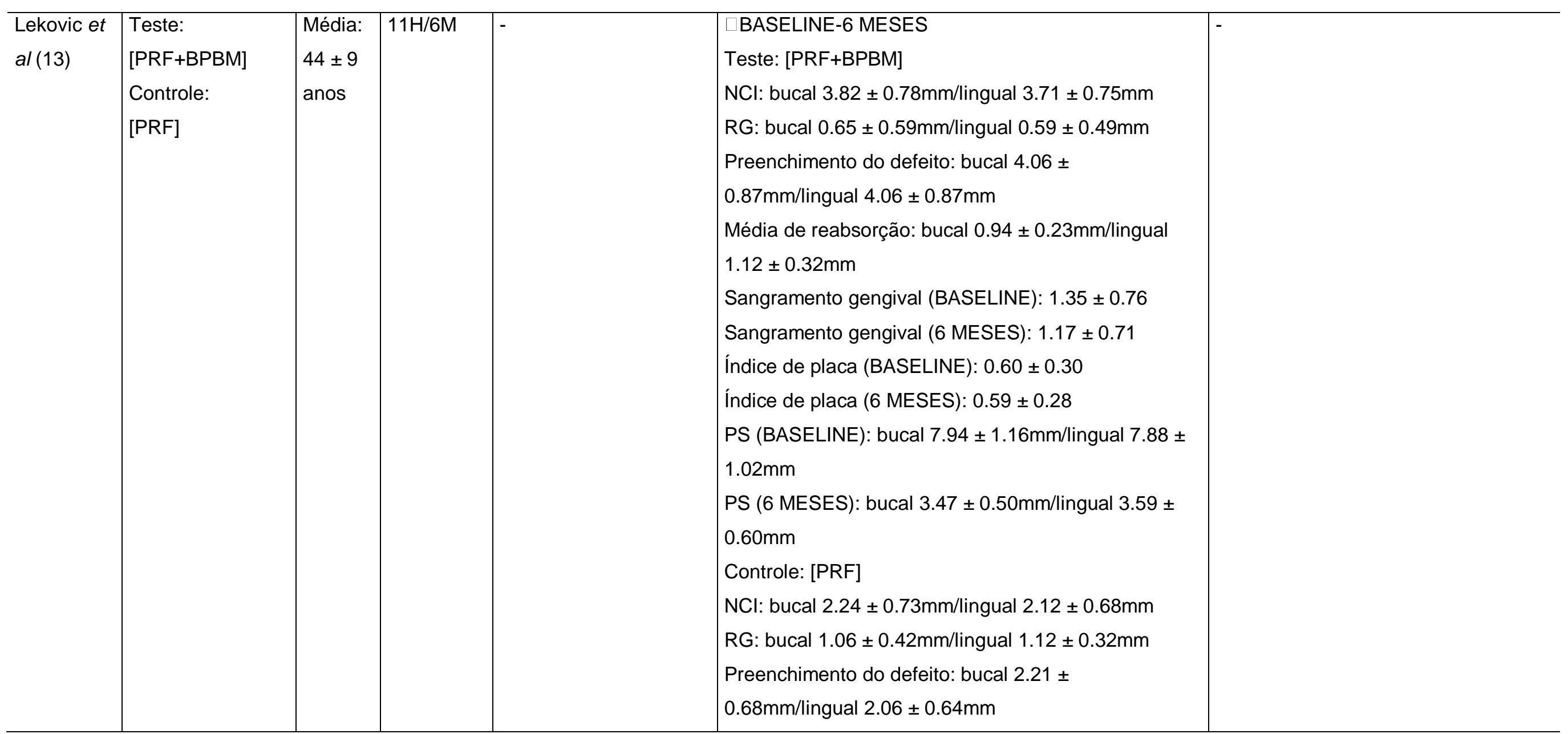




\section{RECIMA21 - REVISTA CIENTÍFICA MULTIDISCIPLINAR}

FIBRINA RICA EM PLAQUETAS NO TRATAMENTO REGENERATIVO ÓSSEO PERIODONTAL: UMA REVISÃO DE ESCOPO Kamily Alves de Carvalho Chiconelo Sanches, Laryssa Macedo de Oliveira, Magda Feres, Juliana Ferreira, Dimorvan Bordin, Belén Retamal-Valdes

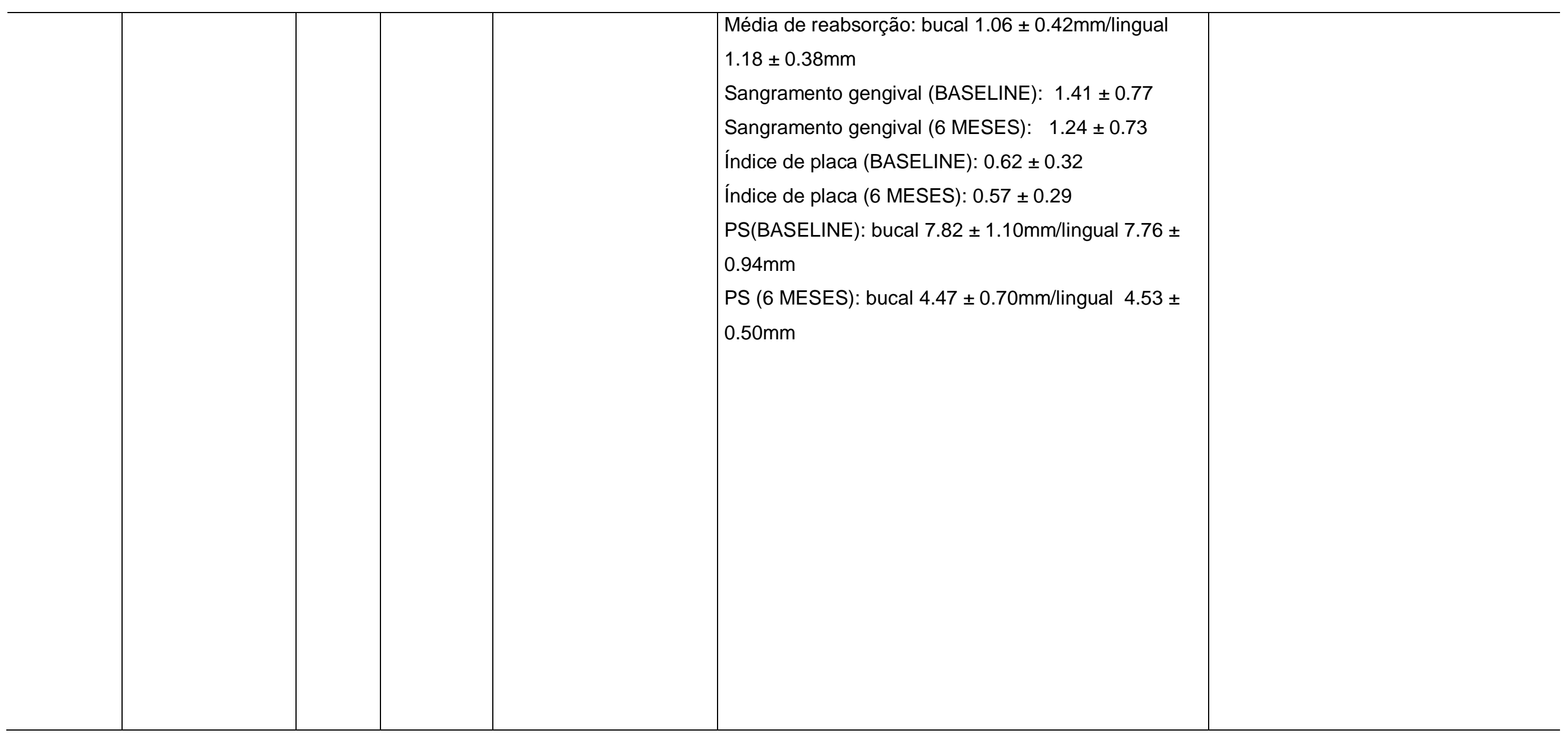




\section{RECIMA21 - REVISTA CIENTÍFICA MULTIDISCIPLINAR}

FIBRINA RICA EM PLAQUETAS NO TRATAMENTO REGENERATIVO ÓSSEO PERIODONTAL: UMA REVISÃO DE ESCOPO Kamily Alves de Carvalho Chiconelo Sanches, Laryssa Macedo de Oliveira, Magda Feres, Juliana Ferreira, Dimorvan Bordin, Belén Retamal-Valdes

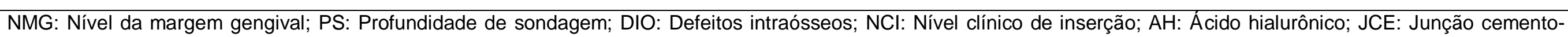

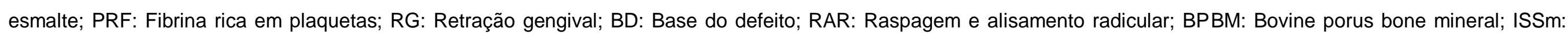

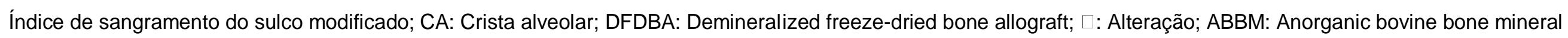

